\title{
INTERVENTION FOR VERB ARGUMENT STRUCTURE IN CHILDREN WITH PERSISTENT SLI: A RANDOMIZED CONTROL TRIAL
}

\author{
Susan H. Ebbels ${ }^{1,2}$, Heather K.J. van der Lely ${ }^{2}$ and Julie E. Dockrell ${ }^{3}$
}

This is an Accepted Manuscript of an article published by the American Speech And Hearing Association in the Journal Of Speech, Language And Hearing Research on October $1^{\text {st }}, 2007$, available online, http://jslhr.pubs.asha.org/article.aspx?articleid=1765555 doi:10.1044/10924388(2007/093).

\footnotetext{
${ }^{1}$ Moor House School, Surrey, UK

${ }^{2}$ Centre for Developmental Language Disorders and Cognitive Neuroscience, Dept of Human Communication Science, University College London, UK

${ }^{3}$ Psychology and Human Development, Institute of Education, London, UK
}

Corresponding author:

Susan Ebbels

Moor House School,

Mill Lane,

Hurst Green,

Oxted,

Surrey,

RH8 9AQ

UK

ebbelss@moorhouseschool.co.uk 
Abstract

PURPOSE: We aimed to establish whether two theoretically motivated interventions could improve use of verb argument structure in pupils with persistent SLI.

METHOD: Twenty-seven pupils with SLI (aged 11;0-16;1) participated in this randomized controlled trial with "blind" assessment. Participants were randomly assigned to one of three therapy groups: Syntactic-semantic, Semantic and Control. All pupils received nine weekly half hour individual therapy sessions. They were assessed on a specifically designed video test pretherapy, post-therapy and at follow-up.

RESULTS: Pupils receiving the Syntactic-semantic and Semantic therapies made significant progress $(\mathrm{d}>1.0)$, which was maintained at follow-up and generalized to control verbs. Both therapies improved linking of arguments to syntax and the Syntactic-semantic therapy tended to increase use of optional arguments. Pupils receiving the Control therapy made no progress.

CONCLUSION: Both methods of argument structure therapy were effective. Comparisons of their effectiveness in specific areas led to the hypotheses that the pupils' initial difficulties with linking resulted from ill-defined semantic representations, whereas their limited use of arguments may have resulted from syntactic difficulties. When therapy is theoretically grounded, it can inform theories, be time limited and effective for older children with SLI. 
Specific Language Impairment (SLI) is estimated to affect approximately $7 \%$ of children (Leonard, 1998; Tomblin et al., 1997). In many cases the language impairment persists into early adolescence (Aram, Ekelman, \& Nation, 1984; Beitchman, Wilson, Brownlie, Walters, \& Lancee, 1996; Botting, Faragher, Simkin, Knox, \& Conti-Ramsden, 2001) and beyond into late adolescence (Stothard, Snowling, Bishop, Chipchase, \& Kaplan, 1998; van der Lely, 2005) and adulthood (Johnson et al., 1999; Mawhood, Howlin, \& Rutter, 2000; Clegg, Hollis, Mawhood, \& Rutter, 2005a). Yet, few studies have been published which investigate language intervention with schoolaged children with SLI, particularly beyond the early school years. Despite evidence that persisting language impairments have severe effects both on children's educational achievements (Aram \& Nation, 1980; Mawhood et al., 2000; Clegg, Hollis, Mawhood, \& Rutter, 2005b) and social adjustment (Silva, Williams, \& McGee, 1987; Howlin, Mawhood, \& Rutter, 2000; Clegg, Hollis, Mawhood, \& Rutter, 2005c), few UK regions provide direct intervention for children over the age of 11 years (Lindsay, Dockrell, Mackie, \& Letchford, 2005). This situation is unlikely to change until more evidence of the effectiveness of intervention with older children is available.

\section{Intervention Targets With Older Children with SLI}

Older children with SLI (e.g., over the age of seven years) continue to have difficulty with many areas of language, including accurate use of verb morphology (Bishop, 1994; Clahsen, Bartke, \& Gollner, 1997; van der Lely \& Ullman, 2001) and some syntactic structures such as passives (Bishop, 1979; van der Lely, 1996; Norbury, Bishop, \& Briscoe, 2001) and 'wh'-questions (van der Lely \& Battell, 2003). Lexical learning studies also reveal that older children with SLI learn fewer novel words than age controls (Oetting, Rice, \& Swank, 1995; Ellis Weismer \& Hesketh, 1996) and this particularly affects verbs (Oetting et al., 1995). Difficulties learning verbs could impact on a range of language dimensions, one of which is verb argument structure. Several studies have indicated verb argument structure is an area of difficulty for these children.

Studies of verb argument structure in spontaneous speech including children with SLI over 7 years have found that compared to age controls, they omit more obligatory arguments and use fewer 
verb alternations (Thordardottir \& Weismer, 2002). However, they perform similarly to language controls in general (King \& Fletcher, 1993; Thordardottir \& Weismer, 2002), although they tend to use verbs which require fewer obligatory arguments and omit more optional arguments (King, 2000). Elicitation studies with this age group have found that children with SLI show significant differences from age and vocabulary controls in their use of verb argument structure. Ingham (1998) found they used fewer complex resultative verb phrases (e.g., kick the shoes under the chair), omitting the optional argument which appears in the prepositional phrase. Ebbels (2005) found older pupils with SLI (aged 11;0-14;11, eleven of whom were participants in the current study) omitted more obligatory arguments for verbs requiring three arguments (on average omitting obligatory arguments on $15 \%$ of the test verbs requiring three arguments, compared to $3 \%$ for their vocabulary and age controls). They also linked arguments to incorrect syntactic positions with change of state verbs, such as fill and cover (discussed in detail below), producing errors such as the lady is filling the sweets into the jar and the lady is covering the scarf on her head. On average, the pupils with SLI made errors on $22 \%$ of these verbs whereas their vocabulary and age controls made errors on only $5 \%$.

Only a few intervention studies including older children with SLI have been published. Some have focused on vocabulary (e.g., McGregor \& Leonard, 1989; Hyde Wright, 1993; Parsons, Law, \& Gascoigne, 2005). Some have targeted specific areas of morphology, for example: is and don't (Leonard, 1975), the pronoun they (Courtwright \& Courtwright, 1976) and past tense morphology (Ebbels, 2007). Some have targeted formation and/or comprehension of particular syntactic structures, for example: questions (e.g., Wilcox \& Leonard, 1978; Ebbels \& van der Lely, 2001; Ebbels, 2007), active and passive sentences (Ebbels \& van der Lely, 2001; Bishop, Adams, \& Rosen, 2006), the dative construction (Ebbels, 2007) and reversible sentences involving prepositions such as under/over, above/below (Bishop et al., 2006). No studies of older children with SLI were found which aimed to improve verb argument structure. However, a single case study has been carried out with a younger child (aged 5;10) (Bryan, 1997). Bryan used a system she 
called 'Colourful Semantics' where she color-coded the thematic roles in a sentence in order to help the child create a variety of sentence structures. After only three months of intervention, his age equivalent score on a simple test of expressive language improved by 12-18 months. However, Bryan's study did not include experimental control and it is therefore difficult to identify intervention specific improvement.

The current study investigates intervention for verb argument structure in older children with SLI using a randomized control trial. The participants were randomly assigned to one of three groups: two groups received two different interventions aiming to improve verb argument structure and the third group received intervention unrelated to verb argument structure and therefore acted as a control group. One of the interventions targeting verb argument structure (called Syntacticsemantic therapy in this study, but also known as 'Shape Coding') is related to Bryan's (1997) system and has been described in detail in Ebbels (2007). This system uses a combination of shapes, colors and arrows to 'code' phrases, parts of speech and morphology respectively. Previous case studies with older children with SLI (aged 11-14 years) have indicated its efficacy at improving comprehension and production of passives and 'wh' questions (Ebbels \& van der Lely, 2001) and comprehension of the ditransitive construction ( $X$ gives $Y Z$ ) (Ebbels, 2007). One aim of this study is therefore to establish whether this system can be used to improve verb argument structure. Its effectiveness is compared with another method of intervention which focuses exclusively on verb semantics (called 'Semantic therapy'), thereby testing whether the syntactic component of the Syntactic-semantic therapy is necessary, or whether a focus on semantics alone is sufficient. Both methods and their rationale are described in detail below.

The two methods of intervention were based on theories of verb argument structure and in particular, linguistic theories regarding the possible nature of the difficulties in this area experienced by children with SLI. This has two advantages: firstly, theoretically grounded interventions are more likely to be effective, and secondly, such interventions can be used to test the theories on which they are based. In this study, we contrasted two methods of intervention with differing 
theoretical underpinnings, both with each other and with a control intervention. The control intervention allowed us to test whether any progress made by the pupils in the argument structure intervention groups was due to the specific intervention they had received or whether non-specific factors such as additional adult attention or 1:1 sessions with a language focus could explain progress. In addition, a control measure was taken (morphological errors) to determine whether any progress made with the argument structure interventions was specific to the target or whether more general changes in language abilities occurred. We investigated the generalization of any progress made by children in the two argument structure interventions to non-targeted verbs, however generalization to discourse contexts was not examined. We also investigated the maintenance of any treatment effects by re-testing the participants three months after intervention had ceased.

When comparing the two argument structure interventions, we first aimed to establish whether the Syntactic-semantic therapy was more effective at improving verb argument structure overall or whether the exclusive focus on semantics provided in the Semantic therapy was sufficient to bring about an equal degree of change. In addition to overall change in performance we compared the two methods on aspects of verb argument structure which have been found to cause particular difficulties for children with SLI: linking arguments to the correct syntactic positions (especially for change of state verbs) and use of obligatory and optional arguments.

\section{Linking arguments to syntactic positions}

Arguments are linked to different syntactic positions for different verbs. Consider for example, the verbs pour versus fill. These two verbs differ in that with pour the argument linked to the Noun Phrase in the direct Object position changes location (e.g., the girl is pouring THE WATER into the cup) whereas with fill it changes state (becomes full) (e.g., the girl is filling THE CUP with water). This reflects an underlying difference in the semantics of these verbs where the focus of the meaning of pour is on the 'Theme' (the argument which changes of location), whereas the focus for fill is on the 'Goal' (the argument representing the place where the Theme ends up). Pinker (1989) and Jackendoff (1990) argue that this focus is captured by the concept of a 'Patient'. 
The Patient is the argument which is 'affected' by the action, regardless of whether it is also a Theme or a Goal. This is a crucial concept as Pinker and Jackendoff also propose a set of rules which link verb semantics to syntactic structure under which the argument with the role of Patient appears in the direct Object position and the argument with the role of Agent in the Subject position. In the initial stages of language learning, some (e.g., Pinker, 1989; Jackendoff, 2002; Bowerman, 1990) hypothesize that children use these linking rules to 'bootstrap' into the syntax of their native language and identify whether the Subject (=Agent) appears before or after the verb. Pinker $(1989$; 1994) labels this process 'semantic bootstrapping', as semantic knowledge is used to bootstrap (or cue the child) into syntax.

In the later stages of language learning, children can use these rules to work out how to use these verbs accurately in a sentence, linking the Agent to the Subject position and Patient to the Object position. Pinker (1989) calls this process 'forward linking'. However, children can only do this if they know the semantics of verbs (in terms of which arguments have the role of Agent and Patient). If they have either inaccurate semantic representations or difficulties with forward linking, errors may result.

Errors with linking arguments to the correct syntactic positions when producing sentences have been reported in studies with typically developing children around three to six years of age (Bowerman, 1982; Gropen, Pinker, Hollander, \& Goldberg, 1991b) and older children with SLI (aged 11-15 years) (Ebbels, 2005). These errors are much more frequent with change of state verbs (such as fill and cover) than with change of location verbs (such as pour and put). Examples include: "Can I fill some salt into the bear?" and "I'm going to cover a screen over me" (Bowerman, 1982), "the lady is filling the sweets into the jar", and "the lady is covering the scarf on her head" (Ebbels, 2005). We now consider the possible explanations for these errors in terms of inaccurate semantic representations and difficulties using forward linking.

We first explore how inaccurate verb semantic representations could lead to such errors, and why these errors should predominate with change of state verbs. When forward linking rules are 
applied, the Agent is linked to the Subject position and the Patient to the direct Object position. However, if a child has assigned the Patient role to the incorrect argument, this argument will be linked erroneously to the direct Object position. Gropen et al. (1991b) found evidence that inaccurate semantic representations in terms of which argument receives the Patient role seemed to be the cause of such errors. The children in their study were more likely to think that the meaning of fill involved pouring, than that something was made full, i.e., they thought that the focus was on the object which changes location rather than the one which changes state.

Change of state verbs may be more susceptible to the formation of inaccurate semantic representations during the learning process than change of location verbs because changes of state are less salient than changes of location (Gentner, 1978). This is likely to be a particular problem for verbs such as fill and cover where one argument changes state (becoming full or hidden) while another changes location (going into or over the Goal). If the change of location is more salient than the change of state, children may assume that the focus of verbs such as filling and covering is on the argument which changes location (i.e., that the Theme is the Patient), rather than the argument which changes state (i.e., the Goal). Thus, inaccurate semantic representations could arise through observational biases.

These observational biases could be overridden in two ways. Firstly, the child may observe situations where the particular manner of change of location does not apply (e.g., a person filling a jar with sweets by placing them in one at a time), leading them to hypothesize that it is the change of state which is crucial to the meaning of the verb, not the manner of change of location. Secondly, the child may use syntax in parallel with observation to predict which argument is the focus of the verb (Fisher, Hall, Rakowitz, \& Gleitman, 1994). This can be achieved by applying linking rules in reverse, a process Pinker $(1989 ; 1994)$ calls 'reverse linking', but has also been called 'syntactic bootstrapping' (Fisher et al., 1994; Gleitman, 1990). For example, fill could be distinguished from pour by noting that when the verb fill appears in a sentence, the Goal appears in the direct object position and therefore is likely to be the Patient, i.e., the focus of fill is on the 'affected' Goal (the 
item which changes state). Thus, if a child uses reverse linking in parallel with observation, they should be able to hypothesize an accurate semantic representation for change of state verbs.

Van der Lely (1994) investigated the ability of children with SLI to use reverse linking to identify the Agents, Themes and Goals of novel verbs purely from a syntactic construction. The participants heard a sentence including a novel verb and had to act out a possible event for the sentence. The children with SLI had more difficulties with this task than language controls. Van der Lely suggested the children with SLI were unable to apply reverse linking, because they had difficulty identifying the grammatical roles (i.e., Subject, Object and oblique Object) of the noun phrases in the sentences. O'Hara and Johnston (1997) carried out a replication of van der Lely's (1994) study, with similar results. However, they suggested that the difficulty with reverse linking lay not in identifying the grammatical roles of the noun phrases, but in remembering which referents were involved and/or which referent was to play which role, due to the significant processing demands of the task. Thus, while these two studies disagree on the underlying reason for the difficulties with reverse linking (syntactic or processing difficulties), they agree that children with SLI have difficulties with this task. Difficulties with reverse linking would mean that children with SLI are more reliant on observational cues than typically developing children, and therefore, due to the observational biases discussed above, may have more inaccurate semantic representations for change of state verbs in terms of which argument is the Patient.

Intervention based on the hypothesis that imprecise verb semantic representations cause linking errors in SLI would focus on improving the precision of the children's verb semantic representations, in particular which argument is the main focus of events involving change of state verbs, that is, which argument receives the Patient role. This could be achieved through use of reverse linking, for example by providing the children with multiple examples of sentences involving the verbs where the Goal is in the direct Object position. However, if children with SLI have particular difficulties with reverse linking (whether for syntactic or processing reasons), this is unlikely to be effective. An alternative intervention could avoid the need to use reverse linking by 
providing the children with direct, explicit information regarding verb semantics, in particular which argument is the Patient. This is the basis of the Semantic therapy (described in detail below).

The second hypothesis regarding the causes of linking errors was that these errors could result from difficulties using forward linking. In order to account for the disproportionate number of errors with change of state verbs, we could hypothesize that for verbs with three arguments, children may link the Theme rather than the Patient to the object position. This would lead to accurate sentences with change of location verbs, where the Theme is also the Patient, but inaccurate sentences with change of state verbs where the Goal (not the Theme) is the Patient. If they link the Theme instead of the Patient to the direct Object position with these verbs, this would lead to linking errors such as "the lady is covering the scarf over her head". However, a study by Gropen, Pinker, Hollander, \& Goldberg (1991a) showed that typically developing children (aged 3;4-8;5) appear to have accurate linking rules. When the children viewed novel events involving a Theme moving onto a Goal causing an obvious and consistent change of state in the Goal (i.e., the Goal is the focus of the event: the Patient), they more often linked the Goal (the Patient) to the direct Object position. Nevertheless, we do not know if children with SLI would also show the same pattern, or if they would link the Theme to the object position.

Van der Lely (1994) investigated the abilities of children with SLI to use forward linking accurately by showing them novel events paired with novel verbs and asking them to create appropriate sentences with these verbs to describe the events. She found that children with SLI had no more difficulty than language matched controls linking arguments to the correct syntactic positions. However, the events all involved change of location verbs. Thus, these events could all be correctly described by linking the Theme to the direct Object position (as the Theme is also the Patient). Thus, van der Lely's study does not allow us to establish whether children with SLI 'know' that the Patient (not the Theme) links to the object position.

Therefore, one aim of our study is to establish whether the pupils with SLI are sensitive to and able to use this rule linking the Patient to the Object position. In order to do this, we compare 
the effectiveness of two interventions. Both inform the pupils which argument is 'affected' with a particular verb (i.e., which is the Patient). Thus, if the errors made by the pupils pre-therapy are due only to assignment of the Patient role to the incorrect argument (i.e., a semantic error), both methods of intervention should be equally effective. However, if the pupils have link the Theme (not the Patient) to the direct Object position, they will continue to make errors even if they have assigned the Patient role to the correct argument. Therefore, one intervention (Syntactic-semantic therapy, described in detail below) also teaches the pupils that the Patient argument links to the direct Object position. Thus, if the pupils had forward linking difficulties pre-therapy, the Syntacticsemantic therapy should be more effective as it should help them to link the Patient (not the Theme) to the direct Object position.

Thus, the two interventions in this study are based on two different hypotheses regarding the underlying source of linking errors: inaccurate semantic representations and difficulties using forward linking. The Semantic therapy focused only on the semantic representations of the verbs, whereas the Syntactic-semantic therapy focused both on semantics and on forward linking. If the pupils improved more with the Syntactic-semantic therapy than the Semantic therapy, we could assume that they had difficulty with forward linking pre-therapy. In contrast, if they improved equally well with both interventions, we could assume that the underlying difficulty was with the verb semantic representations and their ability to use forward linking was not a problem. Thus we predicted either that the Syntactic-semantic therapy would be more effective, or that both interventions would be equally effective.

\section{Obligatory and optional arguments}

The second aspect of argument structure investigated in this study was the use of obligatory and optional arguments. Studies have found children with SLI omit more obligatory arguments (Thordardottir \& Weismer, 2002; Ebbels, 2005) and use fewer optional arguments (King, 2000; Ingham, Fletcher, Schletter, \& Sinka, 1998) than age controls and (in elicitation studies, Ingham et al., 1998; Ebbels, 2005) than vocabulary controls. Thus, children with SLI generally produce 
shorter sentences with fewer arguments, both obligatory and optional. This could result either because the full range of arguments associated with the verb are not specified, or because of difficulty forming longer sentences including more arguments. The two intervention methods used in this study targeted these two areas. The Semantic therapy focused on the range of semantic arguments associated with the verb, whereas the Syntactic-semantic therapy provided the children with instruction, aids and practice in producing sentences with three arguments. Therefore, if the pupils' difficulties with expressing arguments were due to limited knowledge of the range of arguments which could be expressed, both therapies would be equally effective. However, if their difficulties were with forming sentences with more arguments, the Syntactic-semantic therapy would be more effective. Thus, we predicted that in terms of improving use of obligatory and optional arguments, either both interventions would be equally effective, or the Syntactic-semantic therapy would be more effective.

\section{Method}

\section{$\underline{\text { Study design }}$}

This study is a randomized control trial with 'blind' assessment. Twenty-seven pupils with SLI were recruited and assigned to one of three therapy groups, each divided into two phases. Assignment was carried out using the random number function on an Excel spreadsheet to sort the pupils into a random sequence. The order of assignment of the random sequence to therapy group and phase had been pre-determined (i.e., the first nine pupils to the Syntactic-semantic therapy, the next nine to the Semantic therapy and the final nine to Control therapy; the first five of each group received intervention in phase 1 and the remaining four of each group in phase 2).

All pupils in the study were assessed at the beginning of the study, after phase 1 (Autumn term, when five pupils from each group had received intervention) and after phase 2 (Spring term, when the remaining four pupils from each group had received intervention). After a further term, those pupils who had received therapy in Phase 2 were assessed again to provide a follow-up 
measure. Table 1 summarizes the therapy and testing timetable. The first author carried out the random assignment and provided the intervention to all pupils. An assessor, blind to the assignment of the pupils, carried out all assessments.

\section{$\underline{\text { Participants }}$}

Twenty-seven pupils with SLI (aged 11;0-16;1, mean: 13;4 years, SD: 15m) participated in the study, 10 girls and 17 boys. All spoke English as their only language, 25 were White British, one Black British and one Asian British. All pupils had been independently diagnosed as having a specific language impairment and attended a specialist residential school in the UK because of their language needs. The criteria for inclusion in the study were that pupils had intelligible spontaneous speech, no hearing impairment, neurological dysfunction, structural abnormalities or diagnosis of autism or Asperger's syndrome and their parents gave written consent to them taking part. They were also required to have both Expressive and Receptive Language scores on the CELF-3 (UK) (Semel, Wiig, \& Secord, 1995) of -1.5 SD below the mean or lower and performance IQ scores no lower than $-1.5 \mathrm{SD}$ below the mean as measured using the mean of the Matrices and Pattern Construction subtests of the British Ability Scale-II (Elliot, Smith, \& McCulloch, 1996). Although not a criteria for inclusion, all the pupils had a gap of at least 1.5 SD between their Total Language score on the CELF-3 and their Performance IQ; thus they all showed a severe level of language impairment which was significantly lower than their performance IQ. The mean z-scores (and standard deviations) for the 27 pupils on these tests are shown in Table 2.

Participants were randomly assigned to the three therapy groups. The mean ages and $\mathrm{z}-$ scores on the CELF-3 and BAS-II for the three groups are also shown in Table 2. One-way ANOVAs (or Kruskal-Wallis tests for CELF-3 scores, due to floor effects) by therapy group (Syntactic-semantic, Semantic, Control therapy) showed the three groups did not differ significantly in age, $F(2,24)=1.8, p=0.19, \eta p^{2}=0.13$, Expressive Language, $\chi^{2}(2)=1.58, p=0.47$, Receptive Language, $\chi^{2}(2)=0.65, p=0.74$, or Performance IQ, $F(2,24)=0.67, p=0.53, \eta p^{2}=0.05$. 


\section{$\underline{\text { Pre and post-tests }}$}

The test for argument structure used before and after intervention required the pupils to watch 54 short video scenes ( 5 seconds on average) depicting actions involving 18 different verbs (three scenes for each verb) and describe what was happening using a given verb. For each scene, the pupil was shown the video clip once while the tester provided the target verb in the gerund: "this is VERBing". The clip was then repeated and the pupil was asked: "What is happening?" Three practice items at the beginning of the test were used to train the pupils to use the target verb in a complete sentence. These followed the same format as the test items and used the verbs ringing, walking and telling for scenes showing a lady ringing a bell, a man walking to a shed and a lady telling a story to a little girl. Responses were recorded on a DAT tape recorder (TCD-D8) using an external Sony Electret condenser microphone and transcribed later.

The assessor assigned codes to all pupils (different at each testing point). The assessor and the first author transcribed the data and labeled this only with the pupil's code. The first author then carried out the scoring on the coded data and hence was unaware of the identity of the pupils when carrying out the scoring. Only after scoring was complete was she given the codes in order to match the pupils' scores at different testing points and continue with further analyses.

The test was designed to include verbs which should be known to the pupils but have a range of argument structures. Targeted verbs included those where the participants in Ebbels (2005) had experienced the most difficulty: change of state verbs and verbs with three obligatory arguments. A summary of the verbs used is given in Table 3. The test included six change of state verbs, six change of location verbs (four of which have three obligatory arguments, shown in bold in Table 3) and six verbs which undergo the locative alternation (i.e., can appear in either a change of state or change of location form), many of which have three obligatory arguments in the change of location form. The video scenes are listed in Appendix A. The order of the video scenes was randomized using the random number function on an Excel spreadsheet, but then checked by hand to ensure that there was a gap of at least two items between different scenes involving the same 
target verb. The videos were presented in the same random order to each pupil, but the order was changed each time the test was repeated during the year.

The verbs in the test were split into pairs (A and B) where each pair had closely related meanings and argument structures (identified using Levin, 1993). A Wilcoxon signed ranks test showed the A and B verbs did not differ in their written frequencies as identified from the CELEX database (Baayen, Piepenbrock, \& Gulikers, 1995), $W=81.5, n_{1}=9, n_{2}=9, p=0.75$. In order to establish whether any change with therapy was specific to those verbs taught or whether it generalized to other verbs, the pupils in the Syntactic-semantic and Semantic groups were tested on all verbs but only taught half of the verbs. In Phase 1, three pupils from each group focused on A verbs and two on B verbs; in Phase 2, two pupils from each group focused on A and two on B verbs.

\section{$\underline{\text { Scoring }}$}

An overall argument structure score, in terms of proportion correct, formed the primary outcome measure. Responses were only scored as correct if no obligatory arguments were omitted and if the arguments were linked to the correct syntactic positions. The change of state verbs in Table 3 were all required to have the argument which changes state in the object position (as in the description of the scenes in Appendix A). The change of location verbs were required to have the argument which changes location in the object position (see descriptions in Appendix A) and in addition, those shown in bold in Table 3 were required to have a prepositional phrase. An added complication was that some of these verbs can be used with the unaccusative construction (e.g., the shirt is hanging on the washing line). Although the video scenes all involved an agent performing the action and thus a transitive construction was expected (e.g., the man is hanging the shirt on the washing line), use of the unaccusative construction was scored as correct as long as the prepositional phrase was present. For the alternating verbs, where the pupil used the change of state construction (e.g., the lady is wiping the table), they were not required to use a prepositional phrase, 
but where they used the change of location construction, a prepositional phrase was considered obligatory (e.g., the lady is wiping the crumbs off the table, but not *the lady is wiping the crumbs).

For calculating the overall proportion correct scores, errors of lexical selection of the nouns were ignored as long as the referent could be identified, as were errors of selection of prepositions (e.g., use of in for on). Morphological errors unrelated to argument structure were also ignored (although they were recorded for a separate analysis). If the target verb was not used, the sentence was excluded from further analyses. In addition to the overall proportion correct score, three other scores were calculated which formed the secondary outcome measures: (a) proportion of responses where arguments were correctly linked to syntactic positions, (b) proportion of obligatory arguments used and (c) number of optional arguments used. The criteria for including a phrase as an 'optional argument' were similar to King (2000), to aid comparison. We included all objects and prepositional phrases which were optional, semantically related to the verb and functioned with thematic roles such as Theme, Goal, Source or Instrument, for example, she is spilling water onto the floor (Goal), she is spilling water out of a cup (Source), she is wiping the table with a cloth (Instrument) and she is filling the cup with water (Theme). However, prepositional phrases which merely located the whole event were not included, for example, she is spilling water in the kitchen, she is wiping the table in the garden, she is filling the cup in the bathroom.

Inter-rater reliability was assessed by independent coding of one third of the data from each time point by the last author. Inter-rater reliability was $94 \%$. A few of the disagreements were the result of inconsistencies of marking within one or other of the raters and therefore easily resolved. However, the majority of disagreements concerned four verbs: sweep, clear, surround and block. The first disagreement concerned whether sweep and clear can occur without a prepositional phrase when the change of location construction is used (e.g., the man is sweeping/clearing the dust). The second concerned whether surround can be used without a prepositional phrase when an Agent is in Subject position (e.g., the girl is surrounding the animals (with a fence)). The third concerned whether the object in block can be both the passage which is blocked (e.g., the man blocked the toy 
road with a brick) and the object which can no longer pass through the passage (e.g., the man blocked the toy bus with a brick). In order to resolve these differences in judgments, seven independent adults were asked for their judgments and the majority view was used in each case. The majority judged sweep, clear and block to be acceptable with the examples given above, but they judged the example for surround to be unacceptable without the prepositional phrase. All such sentences occurring throughout the study were therefore marked accordingly.

\section{Intervention methods}

All pupils in the study attended a specialist residential school for pupils with SLI and therefore received specialist teaching and therapy throughout the study. Other staff in the school did not carry out focused work on verb argument structure during the period of the study. Random assignment balanced other factors which could contribute to changes in scores. All pupils received nine individual weekly therapy sessions in a quiet room with the first author, lasting approximately 30 minutes each (a total of $4 \frac{1}{2} 2$ hours), in their normal school setting. The intervention methods were planned in advance by the first author who also kept notes for each pupil regarding the activities performed during the session and the pupil's performance. The intervention was carried out by the first author in accordance with the intervention plan and recorded in the session notes. These notes were sufficiently detailed that the last author was able to identify treatment groups from reading the notes with $100 \%$ accuracy. The intervention methods used are described below.

\section{$\underline{\text { Syntactic-semantic therapy }}$}

The Syntactic-semantic therapy was based on the 'Shape Coding' system which was developed for teaching syntax and morphology to children with SLI (Ebbels \& van der Lely, 2001; Ebbels, 2007). In this system, sentences are 'coded' with shapes, colors and arrows to make the syntactic structure of English concrete, permanent and available to inspection and discussion. Different parts of speech are underlined with different colors and the phrases of the sentence are enclosed in shapes. The different shapes correspond to different kinds of phrases and are linked 
with questions such as Who and Where, and symbols (Widget Software Ltd, 1999) to represent these questions (examples are shown in Appendix B). For example, a Verb Phrase is surrounded by a hexagon and linked with the question 'word': What doing. Arguments of verbs appear inside the verb phrase hexagon and adjuncts appear outside it. Verb morphology is also coded with a system of arrows, but these were not used during the argument structure therapy.

The therapy method for this study focused on linking particular syntactic constructions (represented by shape templates) with the two general verb meanings: change of location ('moving') versus change of state ('changing'). Change of location verbs were linked to the construction shown in Figure 1: Subject, Verb, Object, Prepositional Phrase (answering the question Where). The change of state verbs were linked to the construction shown in Figure 2: Subject, Verb, Object, optional Prepositional Phrase (including with - answering the question How) - obligatory arguments have solid lines and optional arguments have dashed lines. These constructions were related to the verb meaning by indicating the type of verbs associated with the construction ('moving' or 'changing' verbs) and hence whether the object moves or changes.

The use of such constructions with alternating verbs can then also be demonstrated, as these are associated with two meanings and two constructions; examples are shown in Figure 3 . The templates can also be used to show why omission of the prepositional phrase with the change of location form changes the meaning, see the last example in Figure 3.

The first two sessions focused on change of location verbs, the next four on change of state verbs and the final three on alternating verbs, although if any pupil had particular difficulties with either change of location or change of state verbs, an extra session focused on that area, reducing the number of sessions spent on alternating verbs. For change of location verbs, the pupil was first introduced to the idea of 'moving' verbs. The therapist and pupil wrote down as many verbs as possible which involved making objects move, using a box of everyday objects to generate ideas. The therapist ensured that all the target verbs for the pupil were on the list. Then, she introduced the shape template: "this is the sentence pattern for describing these actions. We are going to practice 
with these three yellow words". She then wrote down the three targeted change of location verbs for that pupil, for example, spill, hang, put. The therapist and pupil then took turns to be actor and observer, carrying out an action with the everyday objects which could be described with one of the target verbs. The observer then had to create a sentence matching the template to describe the action. The actor judged whether the observer had created a sentence which matched the template or not and gave feedback such as "you missed out the semicircle" or "you didn't say where" (for an omitted prepositional phrase). When the pupil was accurate at both producing sentences using the template and judging the therapist's sentences, the template was removed and the activity repeated. After the sentence had been both produced and judged, the template was retrieved and together the therapist and pupil used the template to judge whether both the original sentence and the judgment were correct. For homework each week, the pupil wrote three sentences for each of the three verbs targeted in the session and draw the sentence template around the words.

The activities followed the same pattern for the change of state verbs. However, the main focus with these verbs was on whether the arguments had been produced in the correct order (i.e., whether the linking of arguments to syntactic positions was correct). Therefore the feedback focused on whether the word in the rectangle (the direct object) changes (correct) or moves (incorrect). An example of feedback for a linking error is 'you said 'you are filling the water'. The water doesn't change, it moves. The jug is changing - it is getting fuller and heavier. You need to say 'you are filling a jug"'. As with the change of location verbs, these activities were initially carried out with the shape template on view; later the template was removed and only used as a final check. As for the change of location verbs, for homework, the pupils wrote three sentences for each of the verbs targeted during the session and drew the sentence template around the words.

The later sessions focused on the alternating verbs. The pupils were told "some "yellow words' can use the moving and changing patterns. But, you have to be careful you don't mix them up". The list of three target verbs was noted and the action, sentence production and judgment activities carried out as before. However, when producing the sentence, the speaker first chose 
which template they wanted to use and pointed to it. Then, if they chose the 'moving pattern' they had to ensure that they included the prepositional phrase ('semi-circle') and if they chose the 'changing pattern' they had to ensure the object which changed was in the rectangle. If the pupil produced a sentence such as "you wiped the crumbs" the therapist showed them that this was the changing pattern and commented that "the crumbs don't change, the table changes. You can chose. You can use the changing pattern and say 'you wiped the table'. Or, you can use the moving pattern, but you have to say 'where'. So you could say 'you wiped the crumbs off the table"'. For homework, the pupils wrote four sentences for each verb, two for each pattern.

\section{$\underline{\text { Semantic therapy }}$}

The aim of the Semantic therapy was to provide the pupils with detailed information about the semantic representations of the targeted verbs. In delivering this intervention, the therapist aimed to provide no syntactic information regarding the argument structure of the verb by only using the verbs in the gerund form for example, "this is pouring", "show me sweeping", "is this filling?"

One or two verbs were targeted each session. First, the change of location verbs, then the change of state verbs and finally the alternating verbs, as this was the order used in the Syntacticsemantic therapy. For each target verb, the therapist and pupil jointly devised a written definition with as much detail as possible. For example, the definitions for fill and pour were similar to the following:

POURING liquid or lots of things go down together

to a new place

\author{
FILLING \\ make something full to the top
}

In order to achieve these definitions, the therapist asked the child to say everything they knew about the verb meaning and she paraphrased this into bullet points. Where the child missed out part of the definition, the therapist carried out an action which violated this and asked the child if that action was an example of the verb. For example if the child said pouring meant dropping 
something into a container, the therapist would paraphrase this to "moving down", "to a new place". Then she would carry out an action which fits this description but is not an example of pouring, for example dropping one marble from a cup into a box. She would then lead the discussion round to how she could change the action to make it pouring, for example using lots of marbles or water, thereby leading to an additional factor in the definition of "liquid or lots of things". Then she would carry out the action with lots of marbles or water, but just letting one marble or one drop of water fall out at a time. This would lead to the addition of the information that the liquid or lots of things have to go down "together".

When the definition had been devised and written down, the therapist and pupil took turns to be actor and observer. The actor enacted an event using a variety of props and then the observer went through each point of the definition deciding if the event matched the definition and identifying each of the items in the event. The therapist deliberately enacted a variety of events that violated one or more points of the definition to ensure that the pupil had a full understanding of the verb. For homework each week, the pupils drew a picture of an action involving the verb(s) targeted that week.

In the later sessions, several verbs were considered together such that their meanings could be compared and contrasted. The therapist / pupil actor enacted a single event which could be described using a variety of verbs and the observer had to decide which verbs could or could not be used to describe the event and why. Thus, the therapy method provided the pupils with child friendly definitions, actively involved them in thinking about the meanings of the verbs and enabled them to compare and contrast related words, all methods which have been recommended for vocabulary instruction in general (Beck, McKeown, \& Kucan, 2002).

In order to verify that the therapist did not use the targeted verbs with their argument structure during the sessions, one session with one child was recorded. The transcription of this session showed that, in accordance with the plan of intervention, neither the therapist nor the pupil used the verb which was the direct focus of the therapy in any form other than the gerund. However, 
both the therapist and the pupil used target verbs from other sessions (cover and put) as the main verb of a sentence when describing other verbs. Indeed, it would be very difficult to avoid the use of a general verb such as put during the therapy sessions. For this reason, it was only required that the therapist did not use it in a sentence during those sessions where this verb was the focus of the week.

\section{Control therapy}

The control therapy aimed to improve the pupils' ability to form inferences when comprehending texts along the lines of Yuill and Oakhill (1988) and hence involved no focus on argument structure. This involved working out 'clues' from the words written in sentences and stories to aid the pupils in drawing inferences. For example in the sentence "Tom's mum shouted at him", the word Tom tells us that he is male, while mum indicates a female, Tom's mum indicates that Tom is probably a child. Shouted tells us his mum is probably cross and Tom has probably done something bad. The children were introduced to the idea of looking for clues and presented with sentences and stories typed with large gaps between the lines. In between the lines, they wrote in all the extra information they had worked out from the clues. Then, the therapist and pupil devised questions which asked about the hidden information, for example "is Tom a boy or a man?", "is Tom's mum happy?”, “why did she shout?”. The pupil devised extra questions for homework. The following session, the story was read out loud to the pupil (without them looking at their notes) and then they were asked their own questions. Because all the pupils in the group worked from the same stories, they were also asked questions devised by other pupils in the study.

Post-hoc analysis of the sentence and story stimuli used revealed that the verbs tested in the argument structure test did not appear in the control condition stimuli with the exception of spill and wrap which both appeared once and put which appeared five times. 


\section{Results}

The performance of the three therapy groups on the argument structure video test when first tested did not differ on the overall proportion correct, $F,(2,24)=1.65, p=0.21, \eta p^{2}=0.12$, correct linking, $F(2,24)=1.83, p=0.18, \eta p^{2}=0.13$ or use of arguments (whether obligatory, $F(2,24)=0.86$, $p=0.44, \eta p^{2}=0.07$ or optional, $\left.F(2,24)=1.88, p=0.18, \eta p^{2}=0.14\right)$. Analyses of performance across the groups revealed that as a group, the pupils showed no difference between their proportion of sentences correctly linked and the proportion of obligatory arguments present, $t(26)=0.46, p=0.65$, $d=0.10$, indicating that they made both kinds of errors to an equal extent. Further analyses revealed that within the category of linking errors, a higher proportion of errors were on change of state verbs than change of location verbs, $t(26)=4.32, p<0.001, d=1.18$. Within the category of omitted arguments, a higher proportion of obligatory prepositional phrases were omitted compared with obligatory objects, $t(26)=7.00, p<0.001, d=1.60$.

The remainder of the results are based on the pupils' scores relative to the time they received intervention: pre-therapy, post-therapy and at follow-up. All pupils completed the nine sessions of therapy to which they were allocated and were assessed at all three time points. The initial analyses focus only on the overall proportion correct, with the three secondary measures of correct linking and use of obligatory and optional arguments being analyzed only in the final section of the results. A summary of the overall proportion correct relative to the time they received intervention is shown in the boxplot in Figure 4.

Inspection of Figure 4 reveals aspects of the data which must be considered before commencing analysis of the relative benefits of the three intervention methods. Although the pupils were randomly allocated to groups and there was no statistical difference between the groups pretherapy, the groups did not have identical scores pre-therapy. Thus, a simple comparison of posttherapy scores would be inappropriate. In contrast, comparisons of gain scores (post-therapy minus pre-therapy) for each pupil would reduce the effect of these pre-therapy differences. However, a few pupils scored near ceiling pre-therapy and had little room for change (although all made at least 
three errors, indicating some weakness in this area, especially considering their age and the simple sentence structures required) while others had very low scores and hence had greater potential for change. Figure 4 also shows that some pupils' scores were outliers compared to the others (shown as circles), being much lower. One pupil in the Syntactic-semantic group was an outlier at every testing point whereas one in pupil in the semantic group was an outlier pre- and post-therapy, but was no longer an outlier at follow-up. While it would have been possible to exclude these outliers, these low-scoring pupils were arguably those who needed the intervention most and therefore removing them from any analysis would be unhelpful. However, the combination of a possible ceiling effect and a few pupils who scored much lower than the others could have led to a potential bias if a simple gain score was used.

In order to include the data from all the pupils without allowing the outliers to bias the results, a "normalized gain score" was used (Hake, 1998). This score measures the actual gain as a proportion of the potential gain for each pupil i.e.: (Time 2 score - Time 1 score)/(1-Time 1 score). This has been claimed to have "maximum dependence on instruction, with minimum dependence on pupils' preinstruction states" (Meltzer, 2002). Two normalized gain scores were calculated for each pupil: one using the post-therapy scores and one using the follow-up scores as Time 2 scores; both used the pre-therapy score as the Time 1 score.

Figure 5 shows the mean normalized gain scores from pre-therapy to post-therapy and pretherapy to follow-up for each of the therapy groups across all verbs (the error bars show one standard deviation). The Syntactic-semantic and Semantic therapy groups appeared to have changed positively compared to their pre-therapy scores while the Control therapy group had not.

This effect was analyzed with a mixed design 2x3 ANOVA with time (normalized gain to post-therapy vs. normalized gain to follow-up) as the within subjects variable and therapy group as the between subjects variable. This revealed no main effect of time, $F(1,24)=1.18, p=0.68$, $\eta p^{2}=0.007$, or interaction of group and time, $F(2,24)=0.45, p=0.65, \eta p^{2}=0.04$ but a significant main effect of group $F(2,24)=6.12, p=0.007, \eta p^{2}=0.34$. Post-hoc Bonferroni corrected $t$-tests revealed this 
was due to a significant difference between the Syntactic-semantic and Control therapies $(p=0.009$, $d=1.31)$ and the Semantic and Control therapies $(p=0.04, d=1.22)$ but no significant difference was found between the Syntactic-semantic and Semantic therapies $(p=1.00, d=0.17)$.

The results were re-analyzed to exclude the results of pupils who scored near ceiling pretherapy, thereby reducing any potential statistical confounds. We removed the six pupils whose pretherapy scores were greater than $90 \%$ correct (i.e., fewer than 6 errors). The pattern of the results was the same ${ }^{1}$. Therefore, the results from all pupils were used in the remainder of this paper.

In order to establish whether the positive gains in the Syntactic-semantic and Semantic therapy groups differed from zero at each time point, one-tailed one sample $t$-tests were carried out. These showed that the normalized gains were significantly different from zero for both methods of intervention at both time points (Syntactic-semantic post-therapy: $t(8)=3.87, p=0.002, d=1.01$, follow-up: $t(8)=2.15, p=0.03, d=0.72$, Semantic therapy post-therapy: $t(8)=3.48, p=0.004, d=1.16$, follow-up: $t(8)=2.32, p=0.02, d=0.78)$. The Control therapy group showed negative changes at both time points.

In summary, both the Syntactic-semantic and Semantic therapy groups showed greater normalized gains than the Control therapy group. The positive gains for the Syntactic-semantic and Semantic therapy groups were significantly different from zero both post-therapy and at follow-up, showing that progress was maintained, although the effect sizes for both groups were smaller at follow-up. The pupils in the Control group showed negative gains both post-therapy and at followup.

\section{$\underline{\text { Generalization to control verbs }}$}

Each pupil in the Semantic-syntactic and Semantic therapy groups was taught only half of the test verbs in Table 3, either group A or B. Therefore it was possible to analyze their change in

\footnotetext{
${ }^{1}$ No main effect of time, $F(1,18)=0.02, p=0.90, \eta p^{2}=0.001$, or interaction of group and time, $F(2,18)=0.40, p=0.68$, $\eta p^{2}=0.04$. Significant main effect of group, $F(2,18)=13.92, p<0.001, \eta p^{2}=0.61$. Significant difference between Syntactic-semantic and Control therapies $(p<0.001)$ and Semantic and Control therapies $(p=0.001)$ but no significant difference between Syntactic-semantic and Semantic therapies $(p=1.0)$.
} 
performance on targeted versus control verbs. Mean normalized gains from baseline can be seen in Figure 6.

A 2x2x2 mixed design ANOVA with time (post-therapy vs. follow-up) and verbs (targeted vs. control) as within subjects variables and therapy group (Syntactic-semantic vs. Semantic) as the between subjects variable revealed no main effects of time, $F(1,15)=0.37, p=0.55, \eta p^{2}=0.02$, verbs, $F(1,15)=1.16, \quad p=0.30, \eta p^{2}=0.07$ or group, $F(1,15)=0.13, p=0.72, \eta p^{2}=0.009$. None of the interactions were significant $\left(p>0.5, \eta p^{2}<0.03\right)$. There were, thus, no differences in degree of normalized gain between the groups or verbs and no difference between the normalized gains immediately post-therapy or at follow-up.

In order to test whether these gains were significant, the normalized gain scores from pretherapy at each time point were compared to zero for each group using a one-tailed one-sample $t$ test. For the Syntactic-semantic group, the normalized gains were significantly different from zero post-therapy both for targeted, $t(8)=2.42, p=0.02, d=0.80$ and control verbs, $t(7)=4.63, p=0.001$, $d=1.64$. However, these gains only showed a trend towards significance by follow-up (targeted verbs: $t(8)=1.43, p=0.09, d=0.48$, control verbs: $t(7)=1.59, p=0.08, d=0.56)$. For the Semantic group, the normalized gains were significantly different from zero post-therapy both for targeted, $t(8)=2.33, p=0.02, d=0.78$ and control verbs, $t(8)=2.83, p=0.02, d=0.98$. However, these gains were only maintained at a significant level by follow-up for control verbs, $t(8)=2.19, p=0.03, d=0.73$ and not targeted verbs, $t(8)=1.12, p=0.15, d=0.38$. These analyses show that the improvements seen post-therapy for both groups were not just on targeted verbs but also generalized to other related verbs. However, the effects on both targeted and control verbs reduced by follow-up and thus failed to reach significance in most analyses.

The next sections investigate the effect of the different interventions on the specific areas of argument structure which form a focus of this study: linking and use of obligatory and optional arguments. Given that time had no effect on the primary outcome measure (the overall argument 
structure normalized gain scores), the gain scores used in the analyses of the secondary outcome measures are averages of the gains to post-therapy and follow-up.

\section{Linking}

The averaged normalized gains (post-therapy and follow-up) in proportion of sentences with correct linking are shown in the boxplot in Figure 7. This shows that the majority of pupils in the Syntactic-Semantic and Semantic groups improved their use of linking, whereas the majority of the control group had negative normalized gains, (i.e., were worse at linking after therapy). Tests of normality showed that for the Semantic group, the scores were not normally distributed due to the outlier shown on the boxplot with a star; this pupil's score was therefore removed from the analyses.

A one-way ANOVA with therapy group as the between subjects variable revealed a significant effect of therapy group, $F(2,20)=7.61, p=0.003, \eta p^{2}=0.43$. Post-hoc Bonferroni corrected $t$-tests revealed this was due to significant differences between the Syntactic-semantic and Control groups, $(p=0.006, d=1.56)$ and the Semantic and Control groups $(p=0.01, d=2.81)$. The Syntacticsemantic and Semantic therapy groups did not differ $(p=1.0, d=0.02)$.

In order to establish whether these averaged normalized gains were significantly different from zero for each group, one-tailed t-tests were used. The averaged normalized gain in correct linking was significantly greater than zero for both the Syntactic-semantic, $t(8)=1.87, p=0.049$, $d=0.62$ and Semantic groups, $\mathrm{t}(6)=6.89, p<0.001, d=2.60)$. The Control group's averaged normalized gain was below zero.

\section{$\underline{\text { Obligatory arguments }}$}

The averaged normalized gains (post-therapy and follow-up) in proportion of obligatory arguments used are also shown in the boxplot in Figure 7. This shows that although the median normalized gain for each group was above zero (particularly for the Syntactic-semantic group), many pupils had negative normalized gains. Tests of normality showed that for the Control group, 
the scores were not normally distributed due to the outlier shown on the boxplot with a star; this pupil's score was therefore removed from the analyses.

A one-way ANOVA with therapy group as the between subjects variable showed no significant effect of therapy group, $F(2,22)=0.07, p=0.93, \eta p^{2}=0.007$. In order to establish whether these average normalized gains were significantly different from zero for each group, one-tailed $t$ tests were used. These showed that while the two argument structure intervention groups used more obligatory arguments after the intervention, their averaged normalized gain score was not significantly different from zero (Syntactic-semantic: $t(7)=0.36, p=0.36, d=0.13$; Semantic: $t(8)=0.46, p=0.33, d=0.15)$. The Control group's normalized gain was below zero.

\section{$\underline{\text { Optional arguments }}$}

When analyzing the use of optional arguments, we used straight gain scores (average of post-therapy and follow-up) and not a normalized gain score as there is no obvious ceiling for the number of optional arguments which can be added. The results are shown in Table 4. This shows a positive gain score for the Syntactic-semantic group, whereas the Semantic and Control groups show very little change.

A one-way ANOVA with therapy group as the between subjects variable showed no significant effect of therapy group, $F(2,24)=0.74, p=0.49, \eta p^{2}=0.06$. In order to establish whether the averaged gains were significantly different from zero for each group, one-tailed $t$-tests were used. The averaged gain in number of optional arguments for the Syntactic-semantic group showed a non-significant trend towards being greater than zero, $t(8)=1.78, p=0.056, d=0.59$. In contrast, the gains for the other two groups did not differ significantly from zero (Semantic: $t(8)=0.0, p=1.0$, $d=0.0$; Control: $t(8)=0.23, p=0.41, d=0.07)$.

\section{Morphological errors}

For each pupil, the total number of morphological errors made at each time point was counted. None of the methods of intervention targeted morphology and therefore any change on this 
measure would be expected to be equal between the three groups. In order to aid comparison with the other analyses, a normalized gain score was used. However, on this occasion, the 'ceiling' would be zero (i.e., no morphological errors), so the maximum 'gain' a pupil can make is from time 1 score to zero, so the formula used was: (Time 2 score - Time 1 score)/(0-Time 1 score). A $2 \times 3$ ANOVA, with time (normalized 'gain' to post-therapy vs. normalized 'gain' to follow-up) as the within subjects variable and group as the between subjects variable revealed no main effects of time, $F(1,18)=1.43, p=0.25, \eta p^{2}=0.07$, group, $F(2,18)=0.17, p=0.84, \eta p^{2}=0.02$, or interaction of group and time, $F(2,18)=1.60, p=0.23, \eta p^{2}=0.15$. A one-tailed one sample $t$-test on the average change in morphological errors for the whole group revealed that the normalized 'gain' in number of morphological errors did not differ significantly from zero, $t(26)=-0.69, p=0.24, d=0.15$.

\section{Discussion}

Pupils in both the Syntactic-semantic and Semantic therapy groups made significantly greater gains in their overall use of verb argument structure than the pupils who received the Control therapy. Progress was maintained at follow-up (although the effect was smaller at this point), showing that the significant effects of the intervention lasted for at least 3 months after it had ceased. Progress also generalized beyond the nine verbs which were targeted in the intervention to other untargeted verbs. This generalization to untargeted verbs and the maintenance of progress indicates that although the intervention targeted only a few verbs and involved only 4.5 hours of therapy, it had a broad effect. Thus, we can conclude that both the Syntactic-semantic and Semantic interventions were effective at improving the overall accuracy of use of verb argument structure in older pupils with SLI.

The fact that the pupils in the Control therapy group made no progress in verb argument structure on either the overall score or any of the sub-scores shows that any non-specific effects of 1:1 language intervention (or indeed from repeated testing) do not enable pupils with SLI to improve their ability to use verb argument structure. Conversely, we can also conclude that the effects of the Syntactic-semantic and Semantic interventions were specific to verb argument 
structure, as changes in the number of morphological errors produced by the three groups showed no group differences.

While this study investigated generalization of gains in argument structure ability to other untargeted verbs, it did not investigate generalization to daily life discourse. This is unfortunate as previous studies with younger children with SLI have found that therapy approaches which are more naturalistic than the approach used in this study have led to greater generalization to discourse contexts (Camarata \& Nelson, 1992; Camarata, Nelson, \& Camarata, 1994; Nelson, Camarata, Welsh, Butkovsky, \& Camarata, 1996). However, the participants in those studies differ from those in our study not only in their age, but also in the nature of their difficulties: the majority having only expressive difficulties. This contrasts with those in our study, who also have receptive difficulties. Thus, it would have been valuable to evaluate whether the more explicit approach used in this study led to generalization of new skills to discourse contexts with these older participants with more pervasive impairments. It would also be of interest to establish whether the effects of treatment were maintained beyond the three-month follow-up period included in this study. Thus, future studies should include discourse measures and follow-up testing at longer time intervals after the completion of intervention.

This study not only aimed to establish which therapy methods were effective overall, but also aimed to investigate their effects on different areas of verb argument structure: linking and use of obligatory and optional arguments. The Semantic therapy was designed specifically to test whether the pupils' ability to link the arguments of a verb to the correct syntactic positions could be improved merely by improving their semantic representations of individual verbs. We aimed to compare this to the Syntactic-semantic therapy, which, in addition to a focus on verb semantics, also focused on forward linking, in particular linking the Patient to the direct Object position. The hypothesis was that if the pupils showed equal progress with both methods of intervention, their difficulty was unlikely to be with forward linking, but rather to lie purely with verb semantic representations. On the other hand, if they had difficulties with forward linking, they would be 
expected to make more progress in this area with the Syntactic-semantic therapy than the Semantic therapy.

The results showed that both groups improved their ability to link arguments to syntactic positions to an equal extent. The Semantic therapy only focused on improving verb semantic representations, in particular which argument is 'affected' (i.e., the Patient). The finding that the children with SLI reduced the number of linking errors to the same extent with this intervention as with the Syntactic-semantic intervention shows that once they had correctly identified the Patient (particularly for change of state verbs), they correctly linked this to the direct Object position. This indicates that their ability to use forward linking was unlikely to be the cause of their errors pretherapy and inaccurate or ill-defined semantic representations (in terms of which argument is Patient) were more likely to have been a factor. When these were corrected, they were able to use forward linking accurately. This result therefore extends van der Lely's (1994) finding that children with SLI can use forward linking for transitive and 'locative' (change of location) verbs and indicates that they can also use forward linking for change of state verbs.

This study did not investigate why the pupils had inaccurate semantic representations pretherapy, although this fits with previous research which has found that children with SLI are slow to establish lexical representations and even when these are established, they can be less precise than controls (Dockrell, Messer, \& George, 2001). In the introduction, we discussed some possibilities for the particular difficulties they have with change of state verbs including an over-reliance on observational cues. Observational biases in favor of changes of location could lead to imprecise semantic representations for change of state verbs. However, if the children use information available from the syntax (using reverse linking), they should be able to over-ride these biases. Hence it is possible that the pupils in this study had difficulties with semantic representations due to difficulties using reverse linking (as indicated in previous studies of children with SLI, van der Lely, 1994). 
We also analyzed the effect of the interventions on the pupils' use of obligatory and optional arguments. Although the two groups receiving the argument structure therapies used more arguments after intervention, these gains were not significant for either obligatory or optional arguments. However, for the Syntactic-semantic group, the gain in use of optional arguments showed a medium effect size and only marginally failed to reach significance. We had expected that the Syntactic-semantic group would show similar gains in use of obligatory arguments and therefore the finding that they improved significantly in their ability to link arguments to syntactic positions but not in their ability to use obligatory arguments was unexpected. This was not due to a smaller potential for improvement on obligatory arguments than on linking as the proportion correct on both these measures did not differ pre-therapy. However, inspection of the normalized gains post-therapy and at follow-up for this group showed that their normalized gains on the two measures were very similar post-therapy, but by follow-up, their use of correct linking had improved further, while their use of obligatory arguments had reduced to pre-therapy levels. Thus, the data from the Syntactic-semantic group indicate that the Syntactic-semantic therapy did increase use of obligatory arguments in the short-term, but this was not maintained three months after therapy ceased.

These findings raise questions regarding why improvements in linking appeared to be more robust than improvements in use of obligatory arguments. It is possible that both therapy methods led to permanent changes in the semantic representations of the verbs, thus when the pupils applied forward linking on subsequent occasions they were able to link the arguments correctly to the syntax. In contrast, the lack of maintenance of the progress with use of arguments indicates that while the practice in producing sentences with more arguments (in the Syntactic-semantic therapy) may have been beneficial in the short-term, this did not appear to lead to a permanent change in performance. It is possible a different method of intervention may have led to better outcomes in this area. However, if, as some have argued (e.g., van der Lely, 2005), the core difficulties in children with SLI lie with syntax, achieving permanent changes in their use of syntax either may 
not be possible or may require more therapy time than changes in semantics. This latter hypothesis is more likely given the success of a version of the Syntactic-semantic therapy at teaching syntactic structures to pupils similar to those in this study (Ebbels \& van der Lely, 2001; Ebbels, 2007), in which they received ten hours of intervention on each structure; that is more than double the number of hours received in this study.

\section{$\underline{\text { Summary and future directions }}$}

This study found both the Syntactic-semantic and Semantic therapies to be effective at improving verb argument structure. Progress generalized to untreated verbs and was maintained three months after the therapy ceased, indicating that a small amount of therapy could have a large effect. When the secondary outcome measures were considered, both methods were effective at improving linking of arguments to syntactic positions and the Syntactic-semantic therapy showed a trend towards increasing the use of optional arguments.

It is possible that for linking, a combination of the two methods of intervention would be more effective than either one in isolation, especially for change of state verbs. This could be investigated in future studies. Such studies could also investigate the breadth of the intervention effect in more detail by testing the pupils on a wider range of control verbs, testing their use of verb argument structure in discourse and also carrying out further follow-up tests at greater time intervals after the end of the intervention. Further follow-up tests are particularly important to establish whether the smaller effect sizes seen at follow-up three months later in this study are maintained, or whether they reduce further. Future studies should also aim to increase the power by including larger numbers of participants, as several of the analyses in this study showed non-significant trends with effect sizes $(d)$ of around 0.5 (usually considered to be a medium effect size, Cohen, 1988).

Any control interventions used should be carefully analyzed to ensure there is no overlap with the target intervention. In this study, three of the verbs which were the focus of the argument structure intervention also appeared in the control intervention (although this seemed to have little 
effect on the outcome). One of these verbs was put which would be difficult to avoid; therefore we would recommend that this verb does not form a target of investigation in future studies.

Future research could also aim to identify the factors in the Syntactic-semantic therapy which led to progress. In particular, the use of the shape templates could be investigated by comparing two methods of intervention which are identical in every way except for the use of shape templates. In this way it would be possible to establish whether the permanent visual cues provided by the shapes aid the pupils or whether the additional production practice is the important variable.

\section{Conclusions}

This randomized control trial provides initial evidence for the effectiveness of intervention for verb argument structure for older pupils with SLI. We studied pupils with receptive (and expressive) language impairments and thus, although we did not focus directly on comprehension, this study provides a first step in answering Law et al.'s (2004) call for "further research investigating the effects of intervention for children with receptive language disorders". It is also the first controlled study (as far as we are aware), which specifically investigates argument structure therapy with language-impaired pupils. The experimental design involved both a control intervention and a comparison of two different methods of intervention, both of which were theoretically motivated. This had several advantages. The use of a control group who received an equal amount of intervention, but on a different language area ruled out any non-specific effects of intervention and the comparison of two different intervention methods allowed us to make inferences regarding the possible mechanisms underlying the pupils' initial difficulties with argument structure and ways of remediating these.

This study contributes towards identifying effective methods of intervention for older pupils with SLI. Intervention studies should be based on detailed assessment and hypotheses regarding the nature of the deficit. This not only enables us to draw theoretical inferences from the results of intervention studies, but should also lead to maximally effective intervention. Thus, theory and therapy need to be closely intertwined to enable us to reach the ultimate goal of all research into 
SLI: to provide each and every individual with SLI with the best possible intervention, thereby enabling them to reach their full potential.

\section{Acknowledgements}

We would like to thank Courtenay Norbury who acted as the 'blind' assessor for this project ,Mike Coleman and Chris Fryer who assisted with the technical construction of the argument structure assessment and the two anonymous reviewers who provided many helpful comments. We would also like to thank the pupils who took part in the study and Moor House School, Surrey, UK for providing the accommodation and equipment for the intervention. This study was completed in partial fulfillment for a PhD by Susan Ebbels at the Center for Developmental Language Disorders and Cognitive Science, University College London. The $\mathrm{PhD}$ was jointly supervised by Julie Dockrell and Heather van der Lely. Special thanks to Moor House School who supported Susan Ebbels' PhD. 



\section{References}

Aram, D. M., Ekelman, B. L., \& Nation, J. E. (1984). Preschoolers with language disorders: 10 years later. Journal of Speech and Hearing Research, 27, 232-244,

Aram, D. M. \& Nation, J. E. (1980). Preschool language disorders and subsequent language and academic difficulties. Journal of Communication Disorders, 13, 159-170,

Baayen, R. H., Piepenbrock, R., \& Gulikers, L. (1995), The CELEX Lexical Database (CDROM), Philadelphia, PA: Linguistic Data Consortium, University of Pennsylvania.

Beck, I., McKeown, M., \& Kucan, L. (2002), Bringing Words to Life: Robust Vocabulary Instruction. Solving Problems in the Teaching of Literacy, New York: Guilford Publications.

Beitchman, J. H., Wilson, B., Brownlie, E. B., Walters, H., \& Lancee, W. (1996). Long-term consistency in speech/language profiles: 1. developmental and academic outcomes. Journal of the American Academy of Child and Adolescent Psychiatry, 35, 804-814,

Bishop, D. V. M. (1979). Comprehension in developmental language disorders. Developmental Medicine and Child Neurology, 21, 225-238, 
Bishop, D. V. M. (1994). Grammatical Errors in Specific Language Impairment Competence Or Performance Limitations. Applied Psycholinguistics, 15, 507550,

Bishop, D. V. M., Adams, C. V., \& Rosen, S. (2006). Resistance of grammatical impairment to computerized comprehension training in children specific and non-specific language impairments. International Journal of Language \& Communication Disorders, 41, 19-40,

Botting, N., Faragher, B., Simkin, Z., Knox, E., \& Conti-Ramsden, G. (2001). Predicting pathways of specific language impairment: What differentiates good and poor outcome? Journal of Child Psychology and Psychiatry and Allied Disciplines, 42, 1013-1020,

Bowerman, M. (1982), Reorganisational processes in lexical and syntactic development, in E. Wanner \& L. Gleitman, eds. (Eds.), Language acquisition: the state of the art, Cambridge: Cambridge University Press.

Bowerman, M. (1990). Mapping Thematic Roles Onto Syntactic Functions - Are Children Helped by Innate Linking Rules. Linguistics, 28, 1253-1289,

Bryan, A. (1997), Colourful Semantics., in S. Chiat, J. Law, \& J. Marshall, eds. (Eds.), Language disorders in children and adults: psycholinguistic approaches to therapy., London: Whurr. 
Camarata, S. M. \& Nelson, K. E. (1992). Treatment Efficiency As A Function of Target Selection in the Remediation of Child Language Disorders. Clinical Linguistics \& Phonetics, 6, 167-178,

Camarata, S. M., Nelson, K. E., \& Camarata, M. N. (1994). Comparison of ConversationalRecasting and Imitative Procedures for Training Grammatical Structures in Children with Specific Language Impairment. Journal of Speech and Hearing Research, 37, 1414-1423,

Clahsen, H., Bartke, S., \& Gollner, S. (1997). Formal features in impaired grammars: A comparison of English and German SLI children. Journal of Neurolinguistics, $10,151-171$,

Clegg, J., Hollis, C., Mawhood, L., \& Rutter, M. (2005c). Developmental language disorders - a follow-up in later adult life. Cognitive, language and psychosocial outcomes. Journal of Child Psychology and Psychiatry, 46, 128-149,

Clegg, J., Hollis, C., Mawhood, L., \& Rutter, M. (2005b). Developmental language disorders - a follow-up in later adult life. Cognitive, language and psychosocial outcomes. Journal of Child Psychology and Psychiatry, 46, 128-149,

Clegg, J., Hollis, C., Mawhood, L., \& Rutter, M. (2005a). Developmental language disorders - a follow-up in later adult life. Cognitive, language and psychosocial outcomes. Journal of Child Psychology and Psychiatry, 46, 128-149, 
Cohen, J. (1988), Statistical power analysis for the behavioural sciences, Hillsdale, NJ: Lawrence Erlbaum Associates.

Courtwright, J. A. \& Courtwright, I. C. (1976). Imitative modelling as a theoretical base for instructing language-disordered children. Journal of Speech and Hearing Research, 19, 651-654,

Dockrell, J. E., Messer, D., \& George, R. (2001). Patterns of naming objects and actions in children with word finding difficulties. Language and Cognitive Processes, $16,261-286$,

Ebbels, S. \& van der Lely, H. (2001). Meta-syntactic therapy using visual coding for children with severe persistent SLI. International Journal of Language \& Communication Disorders, 36, 345-350,

Ebbels, S. H. 2005, Argument structure in specific language impairment: from theory to therapy, PhD, University College London.

Ebbels, S. H. (2007). Teaching grammar to school-aged children with Specific Language Impairment using Shape Coding. Child Language Teaching and Therapy, 23, 67-93,

Elliot, C. D., Smith, P., \& McCulloch, K. (1996). British Ability Scales II. Windsor: NFERNELSON. 
Ellis Weismer, S. \& Hesketh, L. J. (1996). Lexical learning by children with Specific Language Impairment: Effects of linguistic input presented at varying speaking rates. Journal of Speech and Hearing Research, 39, 177-190,

Fisher, C., Hall, D. G., Rakowitz, S., \& Gleitman, L. (1994). When It Is Better to Receive Than to Give - Syntactic and Conceptual Constraints on Vocabulary Growth. Lingua, 92, 333-375,

Gentner, D. (1978). On relational meaning: the acquisition of verb meaning. Child Development, 49, 988-998,

Gleitman, L. (1990). The structural sources of verb meanings. Language Acquisition, 1, 355 ,

Gropen, J., Pinker, S., Hollander, M., \& Goldberg, R. (1991a). Affectedness and Direct Objects - the Role of Lexical Semantics in the Acquisition of Verb Argument Structure. Cognition, 41, 153-195,

Gropen, J., Pinker, S., Hollander, M., \& Goldberg, R. (1991b). Syntax and Semantics in the Acquisition of Locative Verbs. Journal of Child Language, 18, 115-151,

Hake, R. R. (1998). Interactive engagement versus traditional methods: A six-thousandstudent survey of mechanics test data for introductory physics courses. American Journal of Physics, 66, 64-74, 
Howlin, P., Mawhood, L., \& Rutter, M. (2000). Autism and Developmental Receptive Language Disorder: a Follow-up Comparison in Early Adult Life. II: Social, Behavioural, and Psychiatric Outcomes. Journal of Child Psychology and Psychiatry, 41, 561-578,

Hyde Wright, S. (1993). Teaching word-finding strategies to severely language-impaired children. European Journal of Disorders of Communication, 28, 165-175,

Ingham, R., Fletcher, P., Schletter, C., \& Sinka, I. (1998). Resultative VPs and Specific Language Impairment. Language Acquisition, 7, 87-111,

Jackendoff, R. (2002), Foundations of Language: Brain, Meaning, Grammar, Evolution, Oxford: Oxford University Press.

Jackendoff, R. S. (1990), Semantic Structures. Cambridge, MA: MIT Press.

Johnson, C. J., Beitchman, J. H., Young, A., Escobar, M., Atkinson, L., Wilson, B., Brownlie, E. B., Douglas, L., Taback, N., Lam, I., \& Wang, M. (1999). Fourteen-year follow-up of children with and without speech/language impairments: Speech/language stability and outcomes. Journal of Speech Language and Hearing Research, 42, 744-760,

King, G. (2000), Verb complementation in language impaired school age children, in M. Aldridge, ed. (Eds.), Child Language, (pp. 84-91), Cleveden, UK: Mulitlingual Matters. 
King, G. \& Fletcher, P. (1993). Grammatical Problems in School-Age-Children with Specific Language Impairment. Clinical Linguistics \& Phonetics, 7, 339-352,

Law, J., Garrett, Z., \& Nye, N. (2004). Speech and Language Therapy Interventions for Children with Primary Speech and Language Delay or Disorder. The Cochrane Library, Issue 1,

Leonard, L. B. (1975). Developmental considerations in the management of language disabled children. Journal of Learning Disabilities, 8, 44-49,

Leonard, L. B. (1998), Children with Specific Language Impairment, Cambridge, MA: MIT Press.

Levin, B. (1993), English Verb Classes and Alternations. A preliminary investigation., Chicago and London: The University of Chicago Press.

Lindsay, G., Dockrell, J. E., Mackie, C., \& Letchford, B. (2005). Local Educational Authorities' approaches to provision for children with specific speech and language difficulties in England and Wales. European Journal of Special Needs Education, 20, 329-345,

Mawhood, L., Howlin, P., \& Rutter, M. (2000). Autism and developmental receptive language disorder - a comparative follow-up in early adult life. I: cognitive and language outcomes. Journal of Child Psychology and Psychiatry, 41, 547559 , 
McGregor, K. K. \& Leonard, L. B. (1989). Facilitating word-finding skills of languageimpaired children. Journal of Speech and Hearing Disorders, 54, 141-147,

Meltzer, D. E. (2002). The relationship between mathematics preparation and conceptual learning gains in physics: A possible "hidden variable" in diagnostic pretest scores. American Journal of Physics, 70, 1259-1268,

Nelson, K. E., Camarata, S. M., Welsh, J., Butkovsky, L., \& Camarata, M. (1996). Effects of imitative and conversational recasting treatment on the acquisition of grammar in children with specific language impairment and younger language-normal children. Journal of Speech and Hearing Research, 39, 850859

Norbury, C. F., Bishop, D. V. M., \& Briscoe, J. (2001). Production of English finite verb morphology: A comparison of SLI and mild-moderate hearing impairment. Journal of Speech Language and Hearing Research, 44, 165-178,

O'Hara, M. \& Johnston, J. (1997). Syntactic bootstrapping in children with specific language impairment. European Journal of Disorders of Communication, 32, 189-205,

Oetting, J. B., Rice, M. L., \& Swank, L. K. (1995). Quick incidental learning (QUIL) of words by school-age children with and without SLI. Journal of Speech and Hearing Research, 38, 434-445, 
Parsons, S., Law, J., \& Gascoigne, M. (2005). Teaching receptive vocabulary to children with specific language impairment: a curriculum-based approach. Child Language Teaching and Therapy, 21, 39-59,

Pinker, S. (1989), Learnability and Cognition. The Acquisition of Argument Structure, Cambridge, MA: MIT Press.

Pinker, S. (1994). How Could A Child Use Verb Syntax to Learn Verb Semantics. Lingua, $92,377-410$,

Semel, E., Wiig, E. H., \& Secord, W. A. (1995). Clinical Evaluation of Language Fundamentals-3. San Antonio: The Psychological Corporation.

Silva, P. A., Williams, S., \& McGee, R. (1987). A longtitudinal study of children with developmental language delay at age three: later intelligence, reading and behaviour problems. Developmental Medicine and Child Neurology, 29, 630640,

Stothard, S. E., Snowling, M., Bishop, D. V. M., Chipchase, B. B., \& Kaplan, C. A. (1998). Language-impaired preschoolers: a follow-up into adolescence. Journal of Speech Language and Hearing Research, 41, 407-418,

Thordardottir, E. T. \& Weismer, E. (2002). Verb argument structure weakness in specific language impairment in relation to age and utterance length. Clinical Linguistics \& Phonetics, 16, 233-250, 
Tomblin, J. B., Records, N. L., Buckwalter, P., Zhang, X., Smith, E., \& O'Brien, M. (1997). Prevalence of Specific Language Impairment in kindergarten children. Journal of Speech Language and Hearing Research, 40, 1245-1260,

van der Lely, H. K. J. (1994). Canonical Linking Rules - Forward Versus Reverse Linking in Normally Developing and Specifically Language-Impaired Children. Cognition, 51, 29-72,

van der Lely, H. K. J. (1996). Specifically language impaired and normally developing children: Verbal passive vs adjectival passive sentence interpretation. Lingua, $98,243-272$,

van der Lely, H. K. J. (2005). Domain-specific cognitive systems: Insight from Grammatical-specific language impairment. Trends in Cognitive Sciences, 9, 53-59,

van der Lely, H. K. J. \& Battell, J. (2003). Wh-Movement in children with Grammatical SLI: A test of the RDDR hypothesis. Language, 79, 153-181,

van der Lely, H. K. J. \& Ullman, M. T. (2001). Past tense morphology in specifically language impaired and normally developing children. Language and Cognitive Processes, 16, 177-217,

Widget Software Ltd. (1999). Writing with Symbols 2000. 
Wilcox, J. M. \& Leonard, L. B. (1978). Experimental acquisition of Wh-Questions in language-disordered children. Journal of Speech and Hearing Research, 21, 220-239,

Yuill, N. \& Oakhill, J. (1988). Effects of Inference Awareness Training on Poor ReadingComprehension. Applied Cognitive Psychology, 2, 33-45, 


\section{Appendix A: scenes in video test}

\begin{tabular}{|c|c|c|c|c|}
\hline \multicolumn{2}{|c|}{ Verb } & Scene 1 & S cene 2 & S cene 3 \\
\hline & $\begin{array}{l}\text { cover } \\
\text { fill } \\
\text { b lock } \\
\text { surround } \\
\text { build } \\
\text { decorate }\end{array}$ & $\begin{array}{l}\text { lady covering her head with a scarf } \\
\text { lady filling a jar with sweets } \\
\text { man blocking a doorway with stools } \\
\text { girl surrounding animals with a fence } \\
\text { girl building a stable with lego } \\
\text { girldecorating a card with patterns }\end{array}$ & $\begin{array}{l}\text { man covering his dinner with gravy } \\
\text { girl filling a glass with juice } \\
\text { man blocking a watering can with bluetack } \\
\text { man surrounding a table with chairs } \\
\text { girl building a tower with bricks } \\
\text { girl decorating biscuits with icing }\end{array}$ & $\begin{array}{l}\text { lady covering bread with chocolate spread } \\
\text { lady filling a bag with clothes } \\
\text { man blocking a toy road with a brick } \\
\text { girl surrounding a toy bus with blocks } \\
\text { girl building a wall with bricks } \\
\text { mandecorating a tree with tinsel }\end{array}$ \\
\hline & $\begin{array}{l}\text { spill } \\
\text { pour } \\
\text { hang } \\
\text { lean } \\
\text { put } \\
\text { place }\end{array}$ & $\begin{array}{l}\text { lady spilling water on a work top } \\
\text { lady pouring water out of a jug into a sink } \\
\text { lady hanging a coat on a hook } \\
\text { man leaning a ladder against a wall } \\
\text { girl putting a book in her bag } \\
\text { lady placing a vase on a table }\end{array}$ & $\begin{array}{l}\text { lady spilling cereal on a table } \\
\text { lady pouring sweets out of a jar onto a table } \\
\text { man hanging a T shirt on a washing line } \\
\text { man leaning a broom against a table } \\
\text { man putting clothes in a suitcase } \\
\text { lady placing an apple in a bow } 1\end{array}$ & $\begin{array}{l}\text { man spilling a drink on the grass } \\
\text { girl pouring juice into a glass out of a jug } \\
\text { lady hanging a coat over a chair } \\
\text { lady leaning a pencil against a mug } \\
\text { lady putting an apple in a bow } 1 \\
\text { lady placing a lid on a pan }\end{array}$ \\
\hline & $\begin{array}{l}\text { em pty } \\
\text { clear } \\
\text { sw eep } \\
\text { wipe } \\
\text { wrap } \\
\text { stuff }\end{array}$ & $\begin{array}{l}\text { lady emptying a jug of water into a sink } \\
\text { lady clearing a table of cups } \\
\text { lady sweeping the floor } \\
\text { man wiping a table with a cloth } \\
\text { man wrapping a present } \\
\text { man stuffing a chicken }\end{array}$ & $\begin{array}{l}\text { lady emptying sweets out of a jar onto table } \\
\text { lady clearing a table of books } \\
\text { man sweeping leaves off a patio } \\
\text { lady wiping her shoes on a mat } \\
\text { lady wrapping a mug in tisue paper } \\
\text { lady stuffing clothes into a bag }\end{array}$ & $\begin{array}{l}\text { man emptying a glass of ribena (by drinking) } \\
\text { man clearing leaves off a patio } \\
\text { man sweeping cereal off floor into a dustpan } \\
\text { man wiping his face with a flannel } \\
\text { lady wrapping cling film around a sandwich } \\
\text { lady stuffing clothes into a basket }\end{array}$ \\
\hline
\end{tabular}


Appendix B: Shapes, colors, questions and symbols for Syntacticsemantic therapy

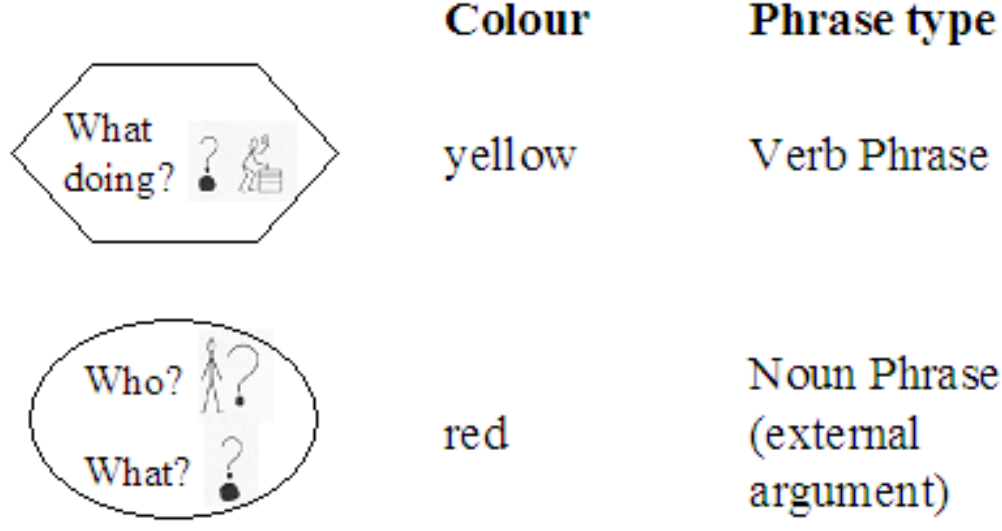

\begin{tabular}{|lc|}
\hline Who? & ?? \\
What? & ? \\
\hline
\end{tabular}

red

Noun Phrase

(internal

argument)

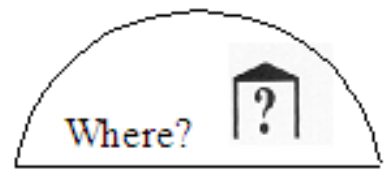

blue

Prepositional

Phrase
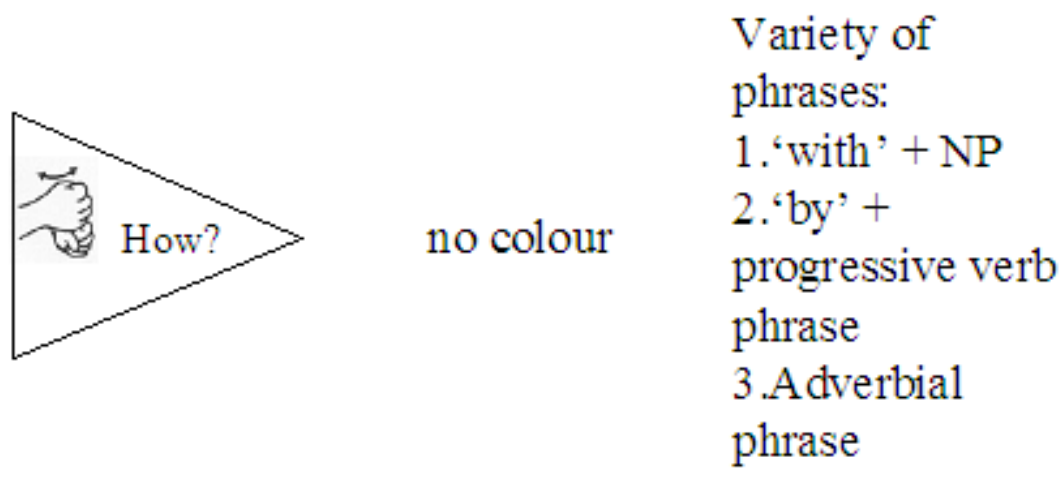
Table 1: Timetable for testing and therapy

\begin{tabular}{lcc}
\hline & Phase 1 children & Phase 2 children \\
\hline Test 1: Sept & pre-therapy test & baseline test \\
Sept-Dec & therapy & \\
Test 2: Dec & post-therapy test & pre-therapy test \\
Jan-Mar & & therapy \\
Test 3: Mar & follow-up test & post-therapy test \\
Test 4: July & & follow-up test \\
\hline
\end{tabular}


Table 2: Mean (SD) ages and z-scores on Performance IQ and CELF-3 overall and for the three therapy groups

\begin{tabular}{llccc}
\hline & & CELF-3 & CELF-3 \\
Therapygroup & Age at Test 1 & Performance IQ & Receptive & Expressive \\
\hline Syntactic-semantic & $13 ; 10(1 ; 4)$ & $-0.14(1.01)$ & $-2.15(0.43)$ & $-2.14(0.40)$ \\
Semantics & $13 ; 6(1 ; 3)$ & $-0.57(0.69)$ & $-2.22(0.26)$ & $-2.34(0.15)$ \\
Control & $12 ; 9(1.3)$ & $-0.67(0.65)$ & $-2.13(0.34)$ & $-2.21(0.35)$ \\
\hline Overall & $13 ; 4(1 ; 3)$ & $-0.51(0.69)$ & $-2.17(0.32)$ & $-2.22(0.34)$ \\
\hline
\end{tabular}


Table 3: Verbs used in video test (bold indicates three arguments required)

\begin{tabular}{lll}
\hline $\begin{array}{c}\text { Change of state } \\
(\mathrm{N}=6)\end{array}$ & $\begin{array}{c}\text { Change of location } \\
(\mathrm{N}=6)\end{array}$ & $\begin{array}{c}\text { Alternating } \\
(\mathrm{N}=6)\end{array}$ \\
\hline A cover & A spill & A clear \\
B fill & B pour & B empty \\
A surround & A hang & A wipe \\
B block & B lean & B sweep \\
A decorate & A put & A wrap \\
B build & B place & B stuff \\
\hline
\end{tabular}


Table 4: Mean gain (post-therapy and follow-up combined)in number of optional arguments used

\begin{tabular}{lc}
\hline Therapy group & M ean gain $(S D)$ \\
\hline Syntactic-semantic & $3.61(6.08)$ \\
Semantic & $0.00(5.89)$ \\
Control & $0.61(8.01)$ \\
\hline
\end{tabular}


Figure 1: Change of location template and example
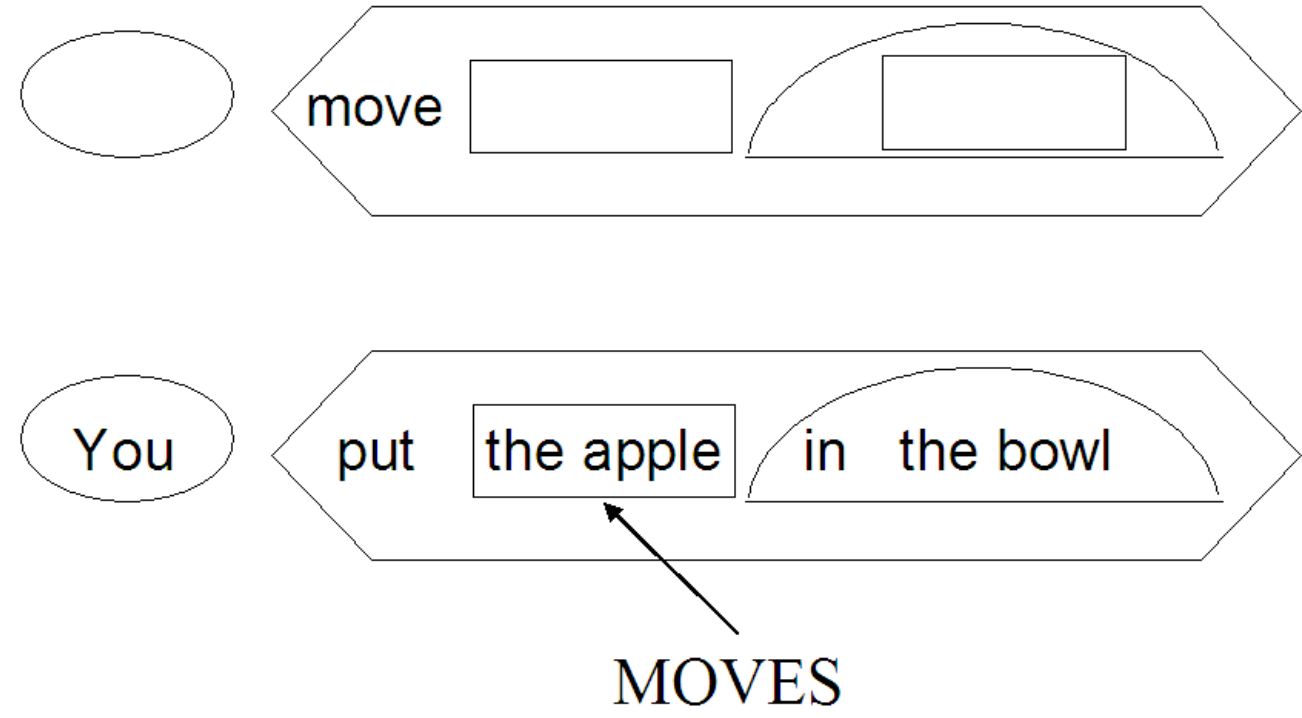
Figure 2: Change of state template and example
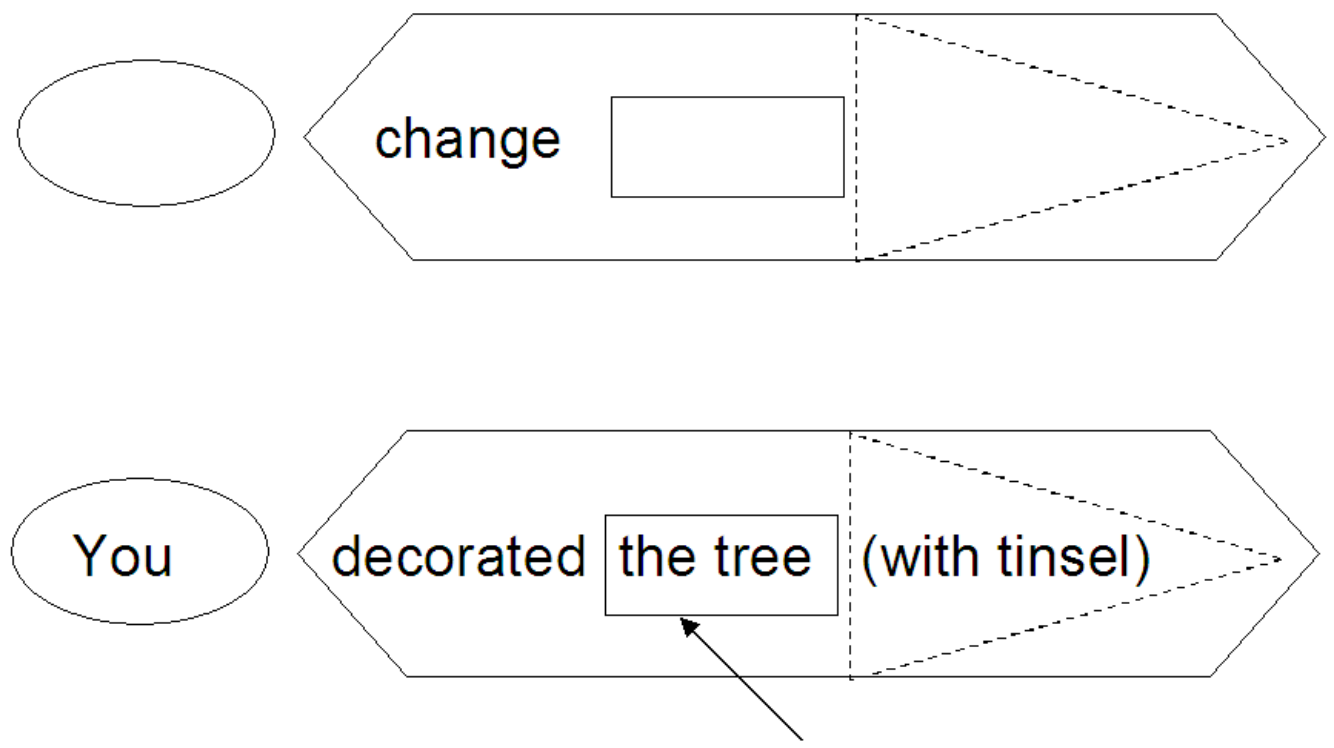

CHANGES (looks prettier) 
Figure 3: Alternating verbs examples
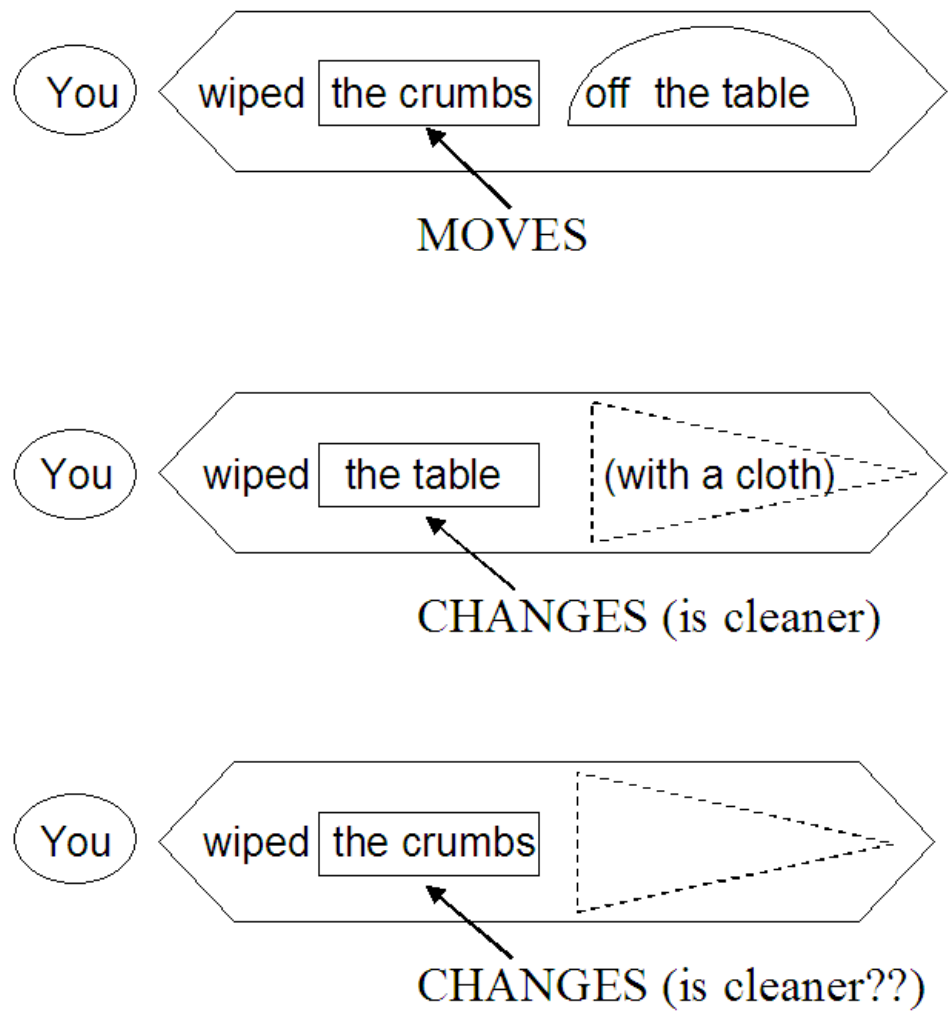
Figure 4: Boxplot showing overall proportion correct by group and time (relative to therapy)

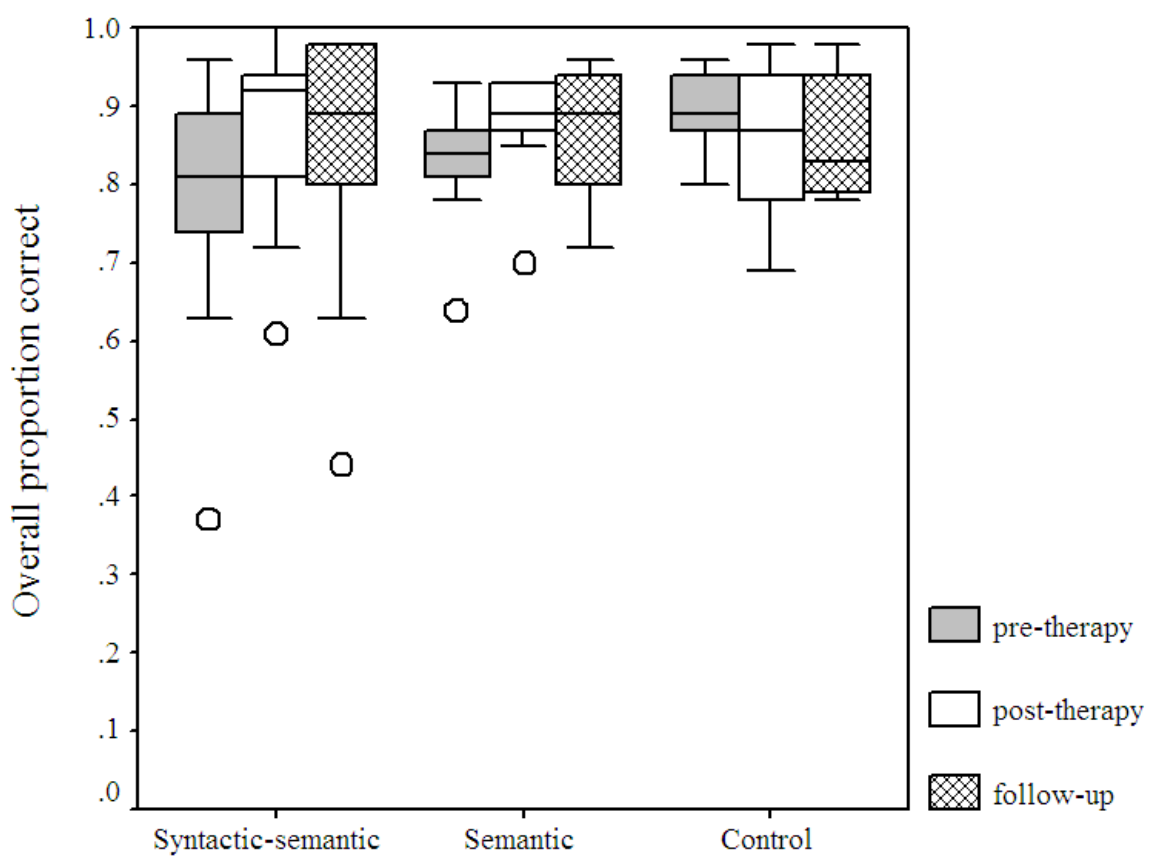

Therapy Group 
Figure 5: Mean normalized gain scores $( \pm \mathrm{SD})$ for overall proportion correct to post-therapy and follow-up (across all verbs)

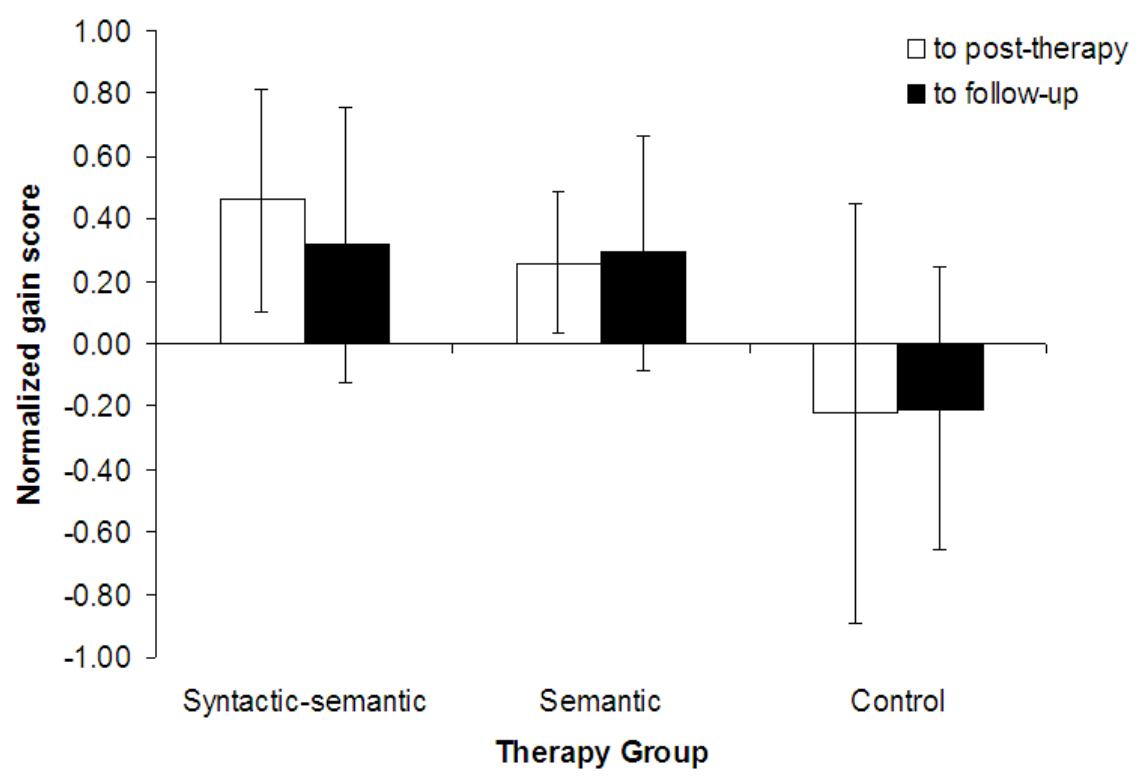


Figure 6: Mean normalized gain $( \pm \mathrm{SD})$ in overall proportion correct in targeted versus control verbs for Syntactic-semantic and Semantics groups

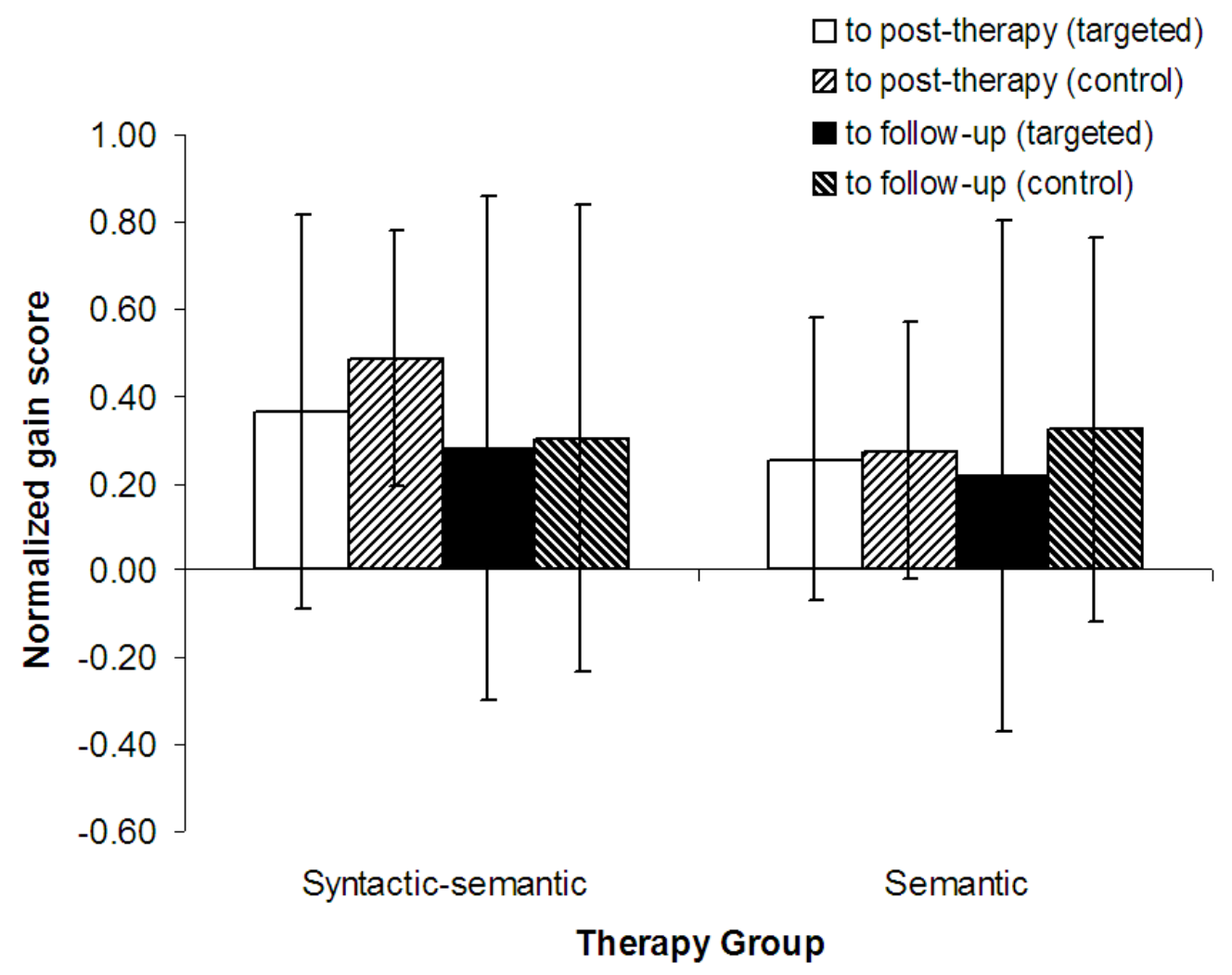


Figure 7: Boxplot showing averaged normalized gain scores for proportion of use of obligatory arguments and correct linking of arguments to syntactic positions

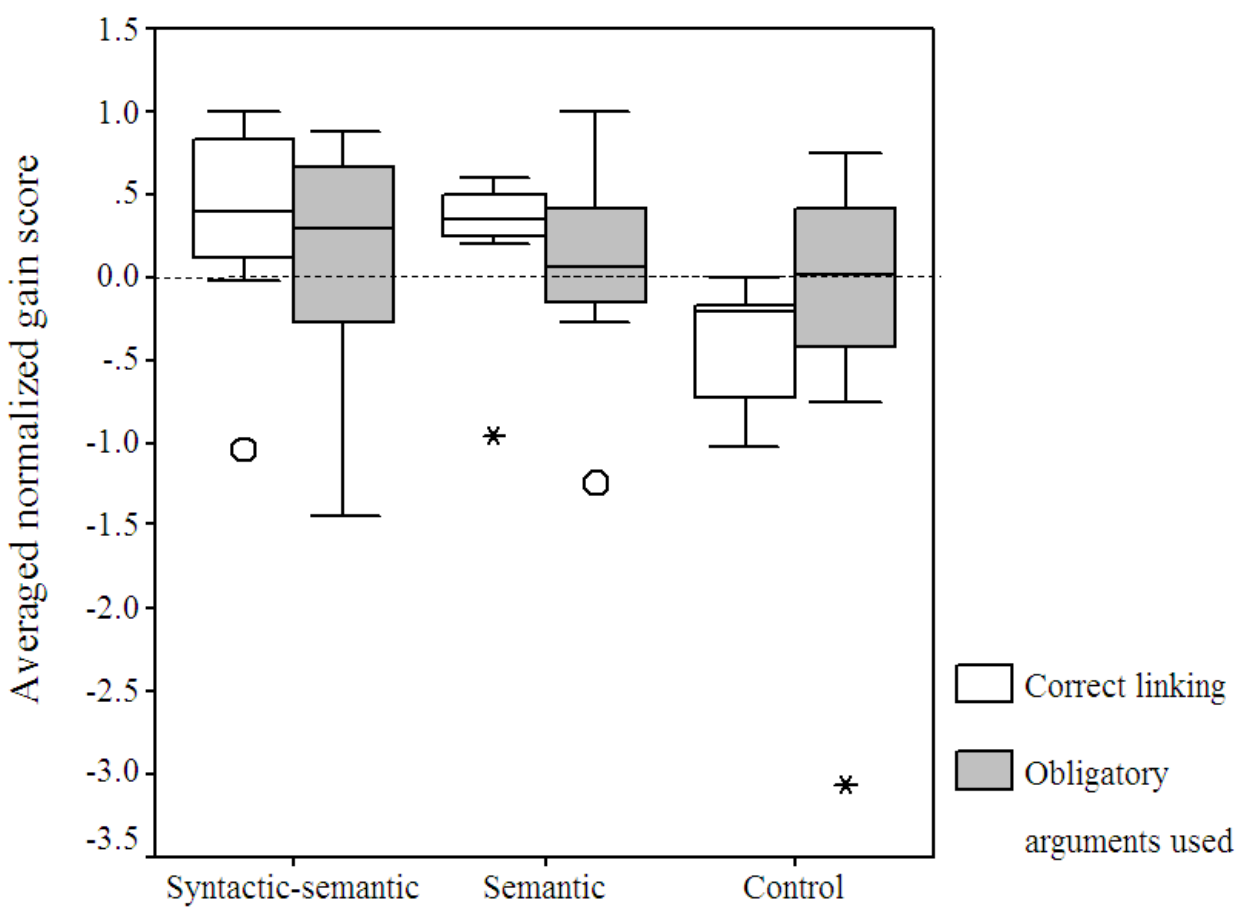

Therapy Group 